University of Rhode Island

\title{
DigitalCommons@URI
}

Open Access Master's Theses

2019

\section{QUANTIFICATION OF VOTING ERROR: THE 2018 RHODE ISLAND MIDTERMS}

Nicholas D. Bernardo

University of Rhode Island, nbernardo@my.uri.edu

Follow this and additional works at: https://digitalcommons.uri.edu/theses

Terms of Use

All rights reserved under copyright.

\section{Recommended Citation}

Bernardo, Nicholas D., "QUANTIFICATION OF VOTING ERROR: THE 2018 RHODE ISLAND MIDTERMS" (2019). Open Access Master's Theses. Paper 1524.

https://digitalcommons.uri.edu/theses/1524

This Thesis is brought to you for free and open access by DigitalCommons@URI. It has been accepted for inclusion in Open Access Master's Theses by an authorized administrator of DigitalCommons@URI. For more information, please contact digitalcommons@etal.uri.edu. 


\section{QUANTIFICATION OF VOTING ERROR:}

THE 2018 RHODE ISLAND MIDTERMS

BY

NICHOLAS D. BERNARDO

\section{A THESIS SUBMITTED IN PARTIAL FULFILLMENT OF THE \\ REQUIREMENTS FOR THE DEGREE OF \\ MASTER OF SCIENCE}

IN

SYSTEMS ENGINEERING

UNIVERSITY OF RHODE ISLAND

2019 


\title{
MASTER OF SCIENCE THESIS
}

$\mathrm{OF}$

\author{
NICHOLAS D. BERNARDO
}

APPROVED:

Thesis Committee:

Major Professor Gretchen Macht

Valerie Maier Speredelozzi

Shanna Pearson-Merkowitz

Nasser H. Zawia

DEAN OF THE GRADUATE SCHOOL 


\begin{abstract}
Studies pertaining to election systems have historically identified paper-based voting systems as better performing than most voting system alternatives. Despite this, there is a lack of literature exploring the use of paper ballots from an in-depth perspective. This study investigates different metrics of ballot length (i.e., words, questions, selections, pages, sheets, and bilingual) and how they impact voting errors (i.e., machine-based errors, human-machine interaction errors, and ballot marking errors) during the 2018 Midterm election in Rhode Island. Logistic regression models are developed to measure the relationship between ballot length and voting errors while controlling for municipal and precinct level demographics. The findings indicate that areas with longer ballots and urban areas significantly increase the odds of encountering voting errors. Among the most contributing measures are the number ballot pages, the number of local questions, and the number of candidate selections allowed on a ballot. These factors significantly increased the odds of experiencing voting errors, in some cases as high as $160 \%$. The statewide impact of these errors is presented and opportunities for future work are shared.
\end{abstract}




\section{Acknowledgement}

I would like to give a special thanks to my academic advisor, Dr. Macht. Thanks to Dr. Macht and the SIS Lab, I have found a love for research and plan to continue conducting it into the foreseeable future. Keep changing the world, Dr. Macht, and continue to do it in your way.

Additionally, I would like to thank Rachel Bartels and James Houghton, my teammates throughout the RI VOTES project. Rachel played a critical role in supporting me as a student and person in the short time that we worked together. Without her encouragement, I would have never had the confidence to pursue a master's degree, let alone a PhD which I plan on pursuing in the near future. And of course, James has always been there to share his knowledge and expertise to help not only his teammates, but anyone he sees in need. Without his programming and statistics skills, the RI VOTES project would not have accomplished nearly what it has.

I would also like to thank my committee members, Dr. Speredelozzi, Dr. PearsonMerkowitz, and Dr. Shwartz for sharing their knowledge and feedback with me throughout the development of my thesis.

Another thanks belong to the Democracy Fund for funding my research as well as the Rhode Island Board of Elections for their willingness to share their expertise and data with the RI VOTES team.

And finally, I would like to thank my friends and family who were extraordinarily understanding when plans were cancelled, and my attention was elsewhere due to my studies. They were always in support of my decisions and encouraged me to follow my own path. Thank you all very much! 
Preface

This thesis is written in a format for submission to the Journal of Electoral Studies. There is no strictly required format, so the Author's Guide states the following:

"Formatting requirements: There are no strict formatting requirements but all manuscripts must contain the essential elements needed to convey your manuscript, for example Abstract, Keywords, Introduction, Materials and Methods, Results, Conclusions, Artwork and Tables with Captions. If your article includes any Videos and/or other Supplementary material, this should be included in your initial submission for peer review purposes. Divide the article into clearly defined sections," (Electoral Studies Author's Guide, 2019).

Therefore, this thesis follows a general manuscript format with page layout following that required by the URI Masters Thesis guide. 
Table of Contents

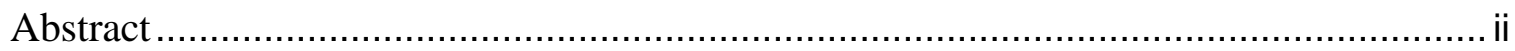

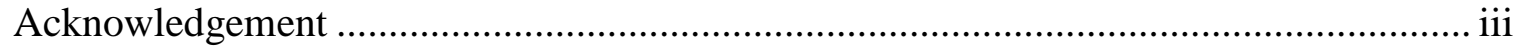

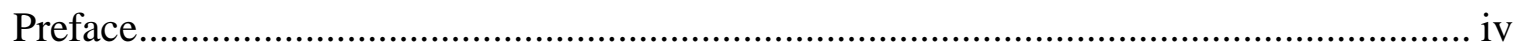

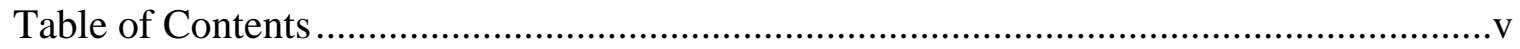

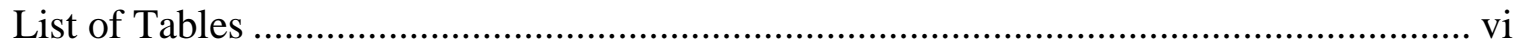

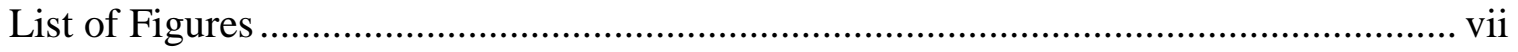

Beginning of the Manuscript "Quantification of Voting Error: The 2018 Rhode Island

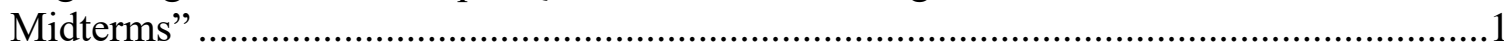

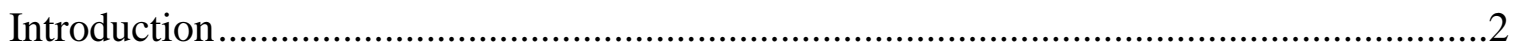

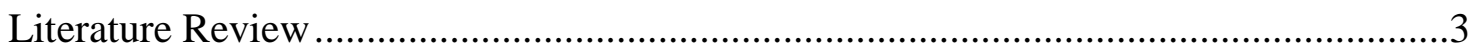

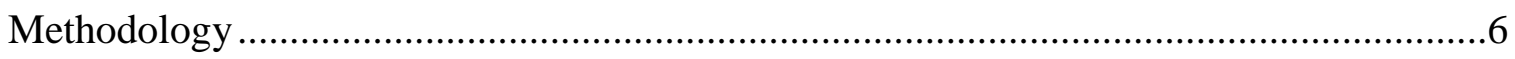

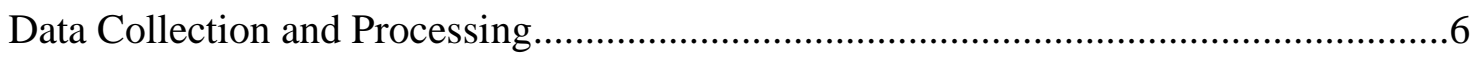

Coding of Ballot Length Measurements ................................................................10

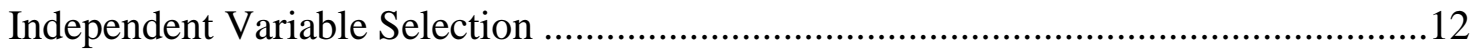

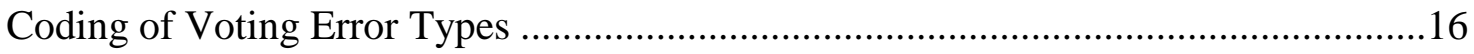

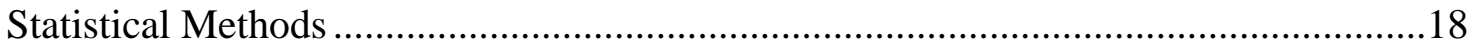

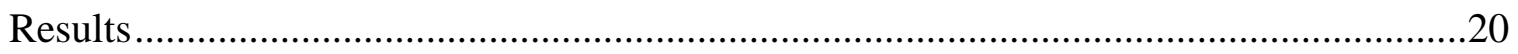

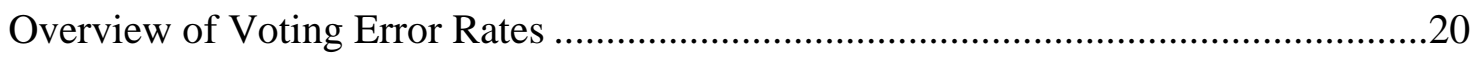

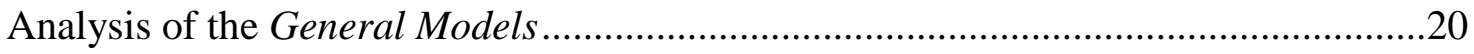

Municipal Level General Model.....................................................................20

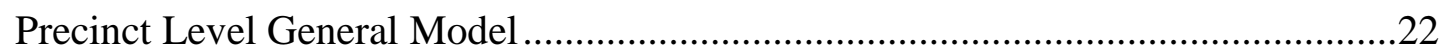

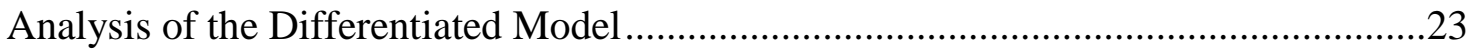

Municipal Level Differentiated Model...............................................................24

Precinct Level Differentiated Model .................................................................28

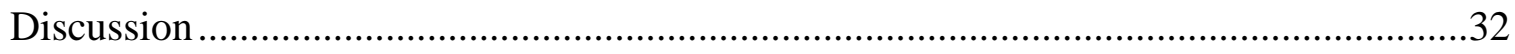

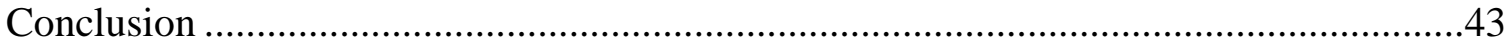

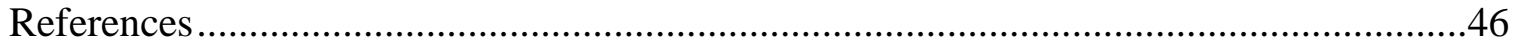

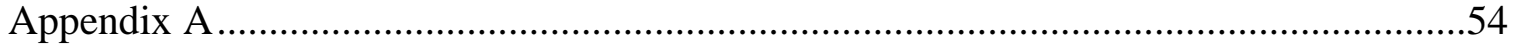

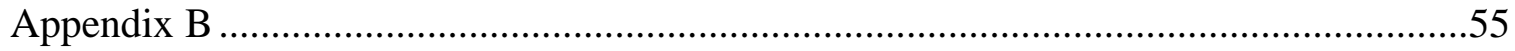

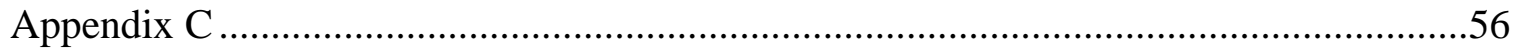

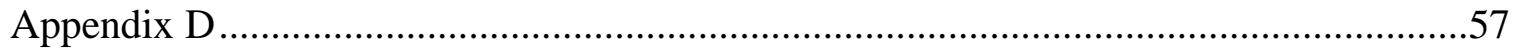

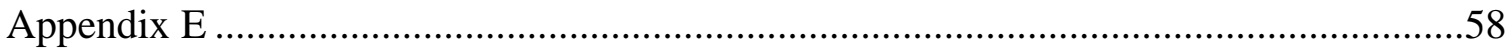


List of Tables

Table 1: Correlation matrix for the independent variables measuring ballot length and municipal level demographic variables........................................... 13

Table 2: Correlation matrix for the independent variables measuring ballot length and precinct level demographic variables.............................................. 14

Table 3: Independent variables per model level.............................. 15

Table 4: Overall error rates by error type in the 2018 RI Midterm election............. 19

Table 5: Municipal level general model results................................... 20

Table 6: Precinct level general model results................................... 22

Table 7: Municipal level differentiated model results................................. 25

Table 8: Directionality of municipal level differentiated model effects.................. 26

Table 9: Precinct level differentiated model results............................... 29

Table 10: Directionality of precinct level differentiated model effects................ 30 
List of Figures

Figure 1: Raw DS200 ballot scanner $\log$ file...................................... 8

Figure 2: Sample ballot questions types: Candidate Questions (left), Local Question

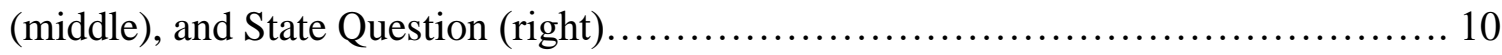


Beginning of the Manuscript "Quantification of Voting Error: The 2018 Rhode Island Midterms"

This manuscript is prepared for submission to the Journal of Electoral Studies. 
Introduction

Throughout the United States (U.S.), as of 2016, 47\% of registered voters lived in a precinct that utilized optical or digital ballot scanners with an additional $19 \%$ of voters living in precincts that utilize both direct recording-electronics (DRE) and optical/digital ballot scanning devices (DeSilver, 2016). These statistics indicate that 74 million voters, in 2016, cast a ballot on an optical/digital ballot scanner while another 29.9 million used either a DRE or an optical/digital scanner (Census Bureau, 2018). These voting systems also continue to show prevalence as institutions encourage the development of Voter Verifiable Paper Audit Trail (VVPAT) compatible systems, of which paper-based ballot scanners show promise (Hall, 2006; Goggin, Byrne, Gilbert, Rogers, and McClendon, 2008). With such an overarching reach within the election system, optical/digital ballot scanners are a key piece of voting equipment to be investigated. These devices indicate when errors occur on a per-ballot sheet basis, indicating that a voter may have selected too many candidates (overvote), generated unreadable marks, or experienced difficulties when interacting with the ballot scanner, all of which have the potential of causing long lines within polling locations and disenfranchising voters. Having access to this error information allows for an assessment of the current state of election systems, as voting technology in recent history has been blamed for voter disenfranchisement and long lines in polling locations (Cassidy, Long, Balsamo, 2018; Jackson, 2000; Levine, 2008). Many states utilize paper ballots and digital ballot scanning devices, exclusively (e.g., Alabama, Connecticut, Iowa, Maine, Rhode Island); thus, with access to ballot scanner data (i.e., log files) and corresponding ballots (i.e., ballot characteristics), an investigation of voting errors associated with ballot scanning can occur. 
This article presents an analysis that utilizes data generated by ballot scanners and ballot characteristics. Relationships between ballot length and voting errors are identified while controlling for municipal level and precinct level demographics, exploring the impact that ballot length has on voting errors in paper-based voting systems. To summarize the goals of this article, the following research questions are presented:

\section{R1: Does ballot length impact the odds of encountering a voting error?}

R2: If so, how does ballot length impact the odds of encountering a voting error?

\section{Literature Review}

Research on voting errors and ballot characteristics has been conducted from several perspectives throughout voting machine and ballot design literature, although the measure of voting error often differs between studies. Lacking a formal definition, "voting error" is classified in the literature as unrecorded votes (Kimball \& Kropf, 2003; Kimball \& Kropf, 2005; Acemyan, Kortum, Byrne, \& Wallach, 2015), roll-off (Reilly \& Richey, 2011), residual votes (Ansolabehere \& Stewart, 2005; Alvarez, Beckett, \& Stewart, 2011), unintentional undervotes and unintentional candidate selection (Herrnson, Hanmer, \& Niemi, 2012; Brady, 2000), or purely undervotes (Schocket, Heighberger, \& Brown, 1992; Bullock \& Hood, 2002). One commonality between these definitions is that the errors are observed after the voting process takes place with no potential for correction, presenting a focus on the impact of errors on election results. A different perspective that goes largely unconsidered is the impact on voters themselves. Examining ballot scanner log files identifies that there are many more types of errors that can occur while marking and scanning a ballot that may not always impact election results but impact the time a voter spends in a polling location. Thus "voting error" in this paper is defined as errors that occur 
during the ballot marking (i.e., marking) and scanning process (i.e., human-machine interaction and machine) as observed by the ballot scanner. While there are many potential causes of voting errors, the potential impact of many ballot characteristics has not been investigated.

Like voting errors, ballot characteristics have many definitions in ballot design literature. Studies that investigate ballot characteristics consider the complexity of ballot questions (Reilly \& Richey, 2011; Milita, 2017), graphic design principles (e.g., the use of bolding, shading, positioning of questions and candidates) (Kimball \& Kropf, 2005), and ballot format (e.g., bubble ballots, connect the arrow ballots, punch card ballots, digital ballots) (Herrnson, Hanmer, \& Niemi, 2012; Bullock \& Hood, 2002; Alvarez, Beckett, \& Stewart, 2013; Ansolabehere \& Stewart, 2005; Shocket, Heighberger, \& Brown, 1992). Another ballot characteristic that has been investigated is ballot length (i.e., the number of questions on a ballot) which increased the variability of a voter's propensity to respond 'yes' or 'no' on Swiss referendums (Selb, 2008). While this study did not explicitly investigate voting error, an effect of ballot length was observed.

While ballot length has been theorized to impact nonresponse rates (i.e., undervotes and blank ballots) (Walker, 1966; Taebel, 1975), little is known about its effects on other types of voting errors (e.g., ballot scanner errors, marking errors). Anecdotally, Elections Officials consider ballot length to be a likely cause of voting errors and literature identifies some effect on voter response variability (Selb, 2008). Despite these implications, direct effects of ballot length on roll-off are found to be insignificant (Reilly \& Richey, 2011). Limited studies investigate the impact of ballot length in real elections and those that do consider only a partial measure of ballot length (e.g., word count) (Reilly \& Richey, 2011). 
The distinct differences in these bodies of work indicate that there is a need for more investigation into the impacts of ballot length on elections, especially with respect to understanding voting error in a real election.

The literature investigating ballot length has conflicting findings regarding its impact on voting. The work of Selb (2008), being one of the few works focusing exclusively on ballot length, identifies that there is in fact some impact of ballot length on elections. However, the study performed in Selb (2008) focusses on Swiss elections and utilizes simulated results. To gain a better understanding of the impact of ballot length, a real Midterm election is investigated. Voting errors are utilized as a proxy for election impact, as they present a cause of delays and voter disenfranchisement in voting systems for individual voters.

H1: Longer ballots lead to an increase in the odds of voting error occurrences. 


\section{Methodology}

The 2018 Rhode Island and Providence Plantations Midterm election was assessed on the municipal level and precinct level to explore the impact of ballot length on the odds of voting errors. Data collected from ballot scanner (DS200) log files, sample ballots, and the American Community Survey (ACS) was used to perform four logistic regression models (i.e., municipal level general model, precinct level general model, municipal level differentiated model, and precinct level differentiated model). Methods used to clean, process, and code the datasets are shared in this section. Statistical methods are described as used throughout the analysis including correlation testing, binary logistic regression, and

multinomial logistic regression. These models are further articulated at the municipal level and precinct level in the following sections.

\section{Data Collection and Processing}

RI was selected for analysis due to the openness of the RI Board of Elections (BOE) to provide data, as well as due to their methods for running elections. RI is the smallest state across the U.S. although it is the second most densely populated ("U.S. States by Density 2019,” 2019). With its small physical size, the RI BOE is able to oversee elections within each municipality and even within each precinct. The 2018 RI Midterm experienced a turnout of 381,267 voters (48.4\% of registered voters), the second highest turnout in the last five Midterm elections (AP News, 2018).

Election data were acquired from two sources in the U.S. 2018 Midterm in RI: (i) ballot scanner log files from digital scanners and (ii) sample ballots. The datasets were stripped of any potential identifying information prior to leaving the possession of the RI 
BOE. In RI, as well as 32 other states as of 2018, DS200 ballot scanners are utilized to tabulate paper ballots (U.S. Election Assistance Commission, 2018). These digital scanning devices produce a transaction log file throughout their use which indicates and records every action that the machine (i.e., DS200) makes. Prior to the 2018 RI Midterm election, sample ballots were distributed for each precinct across RI, which closely resembled the official ballot on Election Day. Both DS200 log files and 2018 sample ballots were provided by the RI BOE and required preprocessing prior to analysis.

A total of 555 ballot scanners were distributed to the 421 precincts during the $2018 \mathrm{RI}$ Midterm. To obtain information about error occurrences, the DS200 log files generated from the ballot scanners were exported into a CSV format and stripped of any identifiable voter information prior to custody. Using a Microsoft Excel package titled BOOTH Voting Package developed by the RI VOTES Project, the files were cleaned and imported into workable Excel files from their raw format.

A sample, compiled DS200 log file is presented in Figure 1 for illustration purposes of the raw data. The average number of lines the machine logged information per the 555 DS200 log files was 2354 with a standard deviation of 1079. Each data file per DS200 log contained the following information, as columns: an event code (an identification code that corresponds to an event type and description), a date, a timestamp, the operating mode (i.e., "E" was seen in all files due to it being activated for an election), a scanner ID number (consistent per log file), the event type, and an event description. Each row of data directly corresponds to a recorded event within the machine, although some rows were not necessary for the purposes of this analysis, such as the setup and 
shutdown procedures, and were automatically detected and removed upon the importing of the data.

Utilizing the event codes, scanning observations (i.e., when a ballot is fully scanned and processed by the scanner) can be obtained. Successful scans (i.e., when a ballot is accepted by the scanner) are recorded in the log files by identifying the beginning (i.e., "Vote Session Started"; ballot is inserted into the scanner) and end (i.e., "Voting Session Complete"; when the ballot is counted) of the interaction, as shown in purple in Figure 1. By identifying the starting and ending codes of scanning observations, an event description was identified for each corresponding scanning observation, thus identifying if the scan was error free or otherwise. There are types of scanning observations that indicated two different types of identification of errors within the sequential lines of codes: (a) one that would be sandwiched within a "Voting Session Started" and a "Voting Session Complete" or (b) one that would keep iterating within the system until completed. Orange boxes in Figure 1 emphasize scanning observations that were accepted by the voter, meaning that their ballot was cast by them despite the error, and thus, would have a beginning event, an error event recorded, and an ending event. Green boxes in Figure 1 highlight scanning observations that contained an error which led to the ballot being returned to the voter with an error and would not result in the end of the interaction. The status of the scan was identified as 'Unsuccessful' if the ballot was returned to the voter (Green in Figure 1) or 'Successful' if the ballot was accepted by the scanner (Purple and Orange in Figure 1) (see Appendix A). Due to the anonymity of the scanning process, the DS200 does not record which sheet of a multi-sheet ballot is being 
processed or where on the ballot errors occur. Ballot length values were therefore taken as a total per ballot.

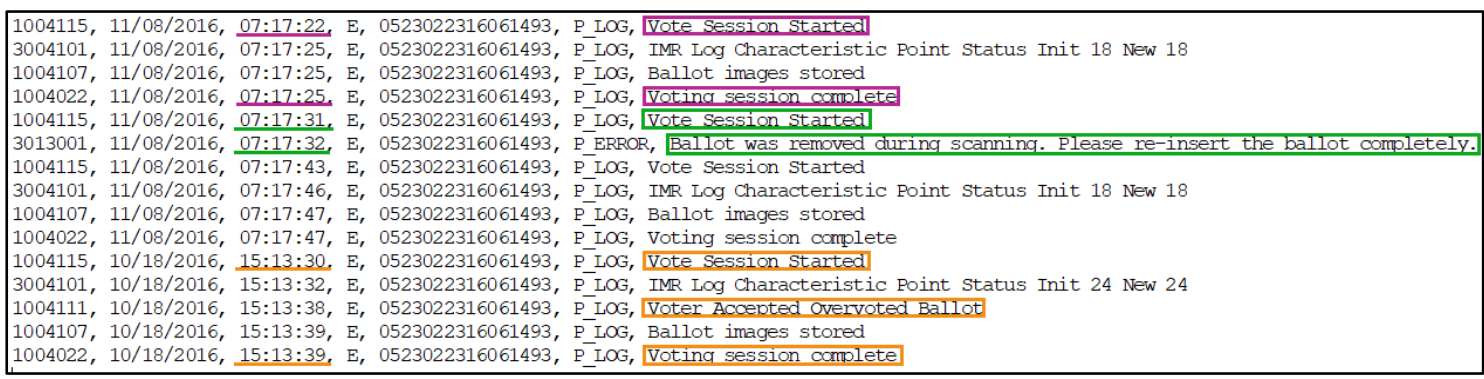

Figure 1: Raw DS200 ballot scanner log file. An error free scanning observation is identified by the code in the purple boxes. The green boxes identify an error that led to a returned ballot. The orange boxes indicate a scanning observation that contained an error but was accepted by the voter. The underlined timestamps are used to calculate the duration of the corresponding observation.

The sample ballots used in this analysis were provided in PDF format for each of the 421 precincts in the 2018 RI Midterm (see Appendix B for a 2018 sample ballot). From these files, measurements of ballot length were determined for each precinct by counting: the number of sheets (i.e., total number of paper sheets) and pages (i.e., summed number of sides), the number of questions in total and type (i.e., national, state, local, candidate, multiple select, referendums), the required number of selections per question, the total number of words per ballot, and whether a ballot contained multiple language translations (see Appendix C for a sample compiled data table). Finally, the scanning observation data and sample ballot data were normalized into a single database by precinct (see Appendix D for a sample).

Demographic data were obtained from the 2017 5-year American Community Survey (ACS) at the municipal level across RI and from the 2016 5-year ACS at the precinct level. Within both the precinct level and municipal level data, the demographics collected were as follows: median income ('Median Income'), percent of the population with a bachelor's degree or greater ('Percent College Educated'), and percent of the population 
that are not white ('Percent Non-white'). The municipal level data also included information regarding the percent of the population living in an urban area ('Urbanicity'). When considering race and ethnicity, the percent of non-white persons was selected due to the large Spanish and Portuguese speaking community with a diverse racial composition in RI. This grouping is more representative of a voting population that may or may not receive a bilingual ballot format which is federally mandated via the Voting Rights Act if 5\% or more of a municipality's population speaks a non-English language (U.S. Department of Justice, 2018).

Seven of the 421 active precincts during the 2018 Midterm election in RI were removed from the dataset. These seven precincts were changed or newly established after the 2016 elections, and therefore had no corresponding demographic data in the 2016 ACS.

\section{Coding of Ballot Length Measurements}

To analyze the impact of ballot length on voting errors, measurements of ballot contents are first defined and gathered. Sample ballots contained a combination of three possible question types: candidate-based questions, state questions, and local questions (Figure 2).

Of these question types, state questions are consistent throughout RI, while only some candidate questions are consistent. The ballots distributed during the 2018 Midterm elections in RI resulted in 39 unique ballots, one for each municipality. 


\begin{tabular}{|c|c|c|}
\hline \multirow{2}{*}{$\begin{array}{l}\text { Moderator } \\
\text { Two Year Term } \\
\text { Vote for } 1\end{array}$} & Local Questions & State Questions \\
\hline & \multirow{3}{*}{$\begin{array}{l}\text { QUESTIONS } 4 \text { - } 6 \\
\text { AMENDMENTS TO THE } \\
\text { BARRINGTON HOME RULE } \\
\text { CHARTER } \\
\begin{array}{l}\text { 4. TOWN COUNCIL MEETINGS } \\
\text { (Amends Section 2-1-9) }\end{array}\end{array}$} & \multirow{2}{*}{$\begin{array}{l}\text { QUESTIONS } 1 \text { - } 3 \\
\text { (Chapter } 047 \text { - Public Laws 2018) }\end{array}$} \\
\hline $\begin{array}{l}\text { Julia P. Califano } \\
\text { DEMOCRAT }\end{array}$ & & \\
\hline Write-in & & $\begin{array}{l}\text { Shall the action of the General } \\
\text { Assembly, by an act passed at the } \\
\text { January } 2018 \text { session, authorizing the } \\
\text { issuance of bonds, refunding bonds, } \\
\text { and/or temporary notes of the State of }\end{array}$ \\
\hline $\begin{array}{l}\text { Town Council } \\
\text { Four Year Term } \\
\text { Vote for any } 2\end{array}$ & \multirow{5}{*}{$\begin{array}{l}\text { Approved by the Town Council June } \\
4,2018 \text { and amended and approved } \\
\text { at the Town Council meeting held on } \\
\text { July } 30,2018 \text {. } \\
\text { Shall the elected Town Council } \\
\text { determine the time of its first } \\
\text { regularly scheduled Town Council } \\
\text { meeting following the Town election } \\
\text { and to meet regularly. }\end{array}$} & \multirow{3}{*}{$\begin{array}{l}\text { Rhode Island for the capital projects } \\
\text { and in the amount with respect to } \\
\text { each such project listed below } \\
\text { (Questions } 1-3 \text { ) be approved, and the } \\
\text { issuance of bonds, refunding bonds, } \\
\text { and/or temporary notes authorized in } \\
\text { accordance with the provisions of said } \\
\text { act? }\end{array}$} \\
\hline $\begin{array}{l}\text { Jacob N. Brier } \\
\text { DEMOCRAT }\end{array}$ & & \\
\hline \multirow{2}{*}{$\begin{array}{l}\text { Stephen B. Primiano } \\
\text { REPUBLICAN }\end{array}$} & & \\
\hline & & \multirow{2}{*}{$\begin{array}{l}\text { 1. RHODE ISLAND SCHOOL } \\
\text { BUILDINGS - } \$ 250,000,000\end{array}$} \\
\hline \multirow{2}{*}{$\begin{array}{l}\text { Michael W. Carroll } \\
\text { DEMOCRAT }\end{array}$} & & \\
\hline & Approve & \multirow{2}{*}{$\begin{array}{l}\text { To provide state assistance to cities } \\
\text { and towns for the construction of new } \\
\text { public schools and renovation of } \\
\text { existing public schools. }\end{array}$} \\
\hline Write-in & $\bigcirc$ Reject & \\
\hline \multirow[t]{2}{*}{ Write-in } & & Approve \\
\hline & & $\bigcirc$ Reject \\
\hline
\end{tabular}

Figure 2: Sample ballot questions types: Candidate Questions (left), Local Question (middle), and State Question (right).

The definition of ballot lengths resulted in the following classifications: the number of pages and/or sides of a ballot with questions listed ('Pages'), the number of physical sheets of paper ('Sheets'), the number of candidate based questions ('Candidate Questions'), the number of local questions ('Local Questions'), the total number of questions ('Total Questions') (Selb, 2008), the maximum number of candidates to be selected ('Candidate Select'), the maximum total number of selections ('Total Select'), and the total word count of the ballot ('Total Words') (Reilly \& Richey, 2011). An additional ballot characteristic, ballot language ('Bilingual'), is included as it directly impacts ballot length as they contain questions listed in English followed by the Spanish translation in RI municipalities which increases the total word count and total space used on a ballot (see Appendix B). The number of selections to be made on a ballot is differentiated between 'Candidate Select' and 'Total Select' due to some office races having several positions available (e.g., town councils, school committees, planning commissions) while other questions, such as 
referendums, offer only one binary selection opportunity (i.e., approve or reject). The measure of 'Total Questions' is the summation of 'Candidate Questions', 'Local Questions', and the statewide questions (three in the 2018 RI Midterm).

To determine which of the proposed measures of ballot length and demographic control variables are included in the model, correlation tests were performed for all combinations of variables. The criterion for acceptance is a correlation coefficient less than 0.8 at a Bonferroni corrected alpha-value of 0.0003 (0.05/158 tests).

Independent Variable Selection

To identify which of the independent variables (i.e., ballot length and demographics) to include in the model, correlations tests were performed (Tables 1 and 2). Several ballot length variables were identified as significantly correlated, thus running into six instances of collinearity.

The measures of 'Pages' and 'Sheets' had a correlation coefficient of 0.961 (p-value = 0.000). 'Pages' was selected to remain in the models as it measures ballot length with more granularity than 'Sheets', as a single 'Sheet' can have either one or two 'Pages'. 'Total Words' also shared a significant correlation coefficient of 0.905 with 'Pages'. 'Pages' was chosen to remain in the model as the additional ballot pages corresponds with additional scanning observations per ballot.

‘Total Questions' and 'Local Questions' are also highly correlated with a coefficient of 0.928, as expected, the number of 'Local Questions' varies between municipalities and plays a role in the total number of questions that appear on a ballot. 'Local Questions' was selected to remain in the model due to the exclusion of the number of statewide questions in its measurement. Another highly correlated pair of ballot length variables was 'Total 
Select' and 'Candidate Select' (0.863). 'Candidate Select' is selected to remain in the models due to the potential for multiselect questions in the candidate-based portion of the ballot, and due to its lower correlation coefficients with the included variables (i.e., 'Pages', 'Candidate Questions', 'Local Questions', and 'Bilingual').

The remaining ballot length variables are 'Candidate Questions' and 'Bilingual'. These variables are included in the model because 'Candidate Questions' accounts for the potential variation in candidate-based questions on ballots from municipality-tomunicipality and 'Bilingual' ballots tend to be longer and present questions in a different format than single language ballots.

Performing the correlation tests for the control variables (i.e., demographic variables) at the municipal level, shown in Table 1 , result in only one collinearity between municipal level demographics and ballot length variables. The collinearity present is between 'Bilingual' and 'Percent Non-white' at the municipal level (i.e., correlation coefficient = 0.895 and $\mathrm{p}$-value $=0.000)$; 'Percent Non-white' is chosen to remain in the model over 'Bilingual'. Among the precinct level demographics, shown in Table 2, no collinearities are present. Therefore, all precinct level variables are included in both the general model and the differentiated model. 
Table 1: Correlation matrix for the independent variables measuring ballot length and municipal level demographic variables.

\begin{tabular}{|c|c|c|c|c|c|c|c|c|c|c|c|c|c|}
\hline & \multicolumn{13}{|c|}{ Independent Variables } \\
\hline & 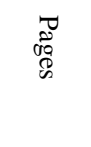 & 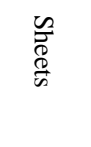 & 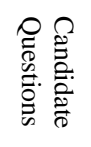 & 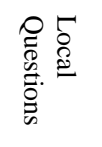 & 品: & 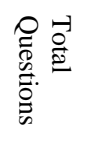 & 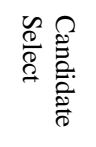 & 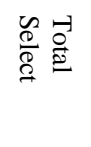 & 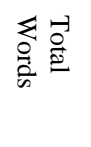 & 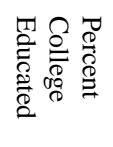 & 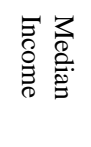 & 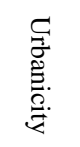 & 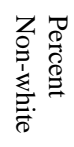 \\
\hline Pages & - & & & & & & & & & & & & \\
\hline Sheets & 0.961 & - & & & & & & & & & & & \\
\hline $\begin{array}{l}\text { Candidate } \\
\text { Questions }\end{array}$ & 0.059 & 0.040 & - & & & & & & & & & & \\
\hline $\begin{array}{l}\text { Local } \\
\text { Questions }\end{array}$ & 0.650 & 0.532 & 0.263 & - & & & & & & & & & \\
\hline Bilingual & 0.585 & 0.634 & -0.163 & 0.219 & - & & & & & & & & \\
\hline $\begin{array}{l}\text { Total } \\
\text { Questions }\end{array}$ & 0.559 & 0.455 & 0.605 & 0.928 & 0.118 & - & & & & & & & \\
\hline $\begin{array}{l}\text { Candidate } \\
\text { Select }\end{array}$ & 0.365 & 0.415 & 0.471 & 0.315 & 0.046 & 0.443 & - & & & & & & \\
\hline $\begin{array}{l}\text { Total } \\
\text { Select }\end{array}$ & 0.599 & 0.572 & 0.468 & 0.751 & 0.149 & 0.801 & 0.863 & - & & & & & \\
\hline $\begin{array}{l}\text { Total } \\
\text { Words }\end{array}$ & 0.905 & 0.816 & -0.009 & 0.728 & 0.603 & 0.597 & 0.194 & 0.522 & - & & & & \\
\hline $\begin{array}{l}\text { Percent } \\
\text { College } \\
\text { Educated }\end{array}$ & -0.492 & -0.537 & -0.065 & -0.190 & -0.529 & 0.597 & 0.102 & -0.030 & -0.456 & - & & & \\
\hline $\begin{array}{l}\text { Median } \\
\text { Income }\end{array}$ & -0.389 & -0.439 & 0.134 & -0.079 & -0.742 & -0.013 & 0.180 & 0.083 & -0.382 & 0.780 & - & & \\
\hline Urbanicity & 0.158 & 0.172 & -0.321 & 0.153 & 0.277 & 0.002 & -0.359 & -0.168 & 0.162 & -0.174 & -0.421 & - & \\
\hline $\begin{array}{l}\text { Percent } \\
\text { Non-white }\end{array}$ & 0.415 & 0.396 & -0.160 & 0.187 & 0.895 & 0.093 & -0.184 & -0.029 & 0.485 & -0.455 & -0.760 & 0.364 & - \\
\hline
\end{tabular}

All correlations are found to be significant with a p-value $<0.0003$. Bolded observations are considered highly correlated $(>=|0.8|)$. 
Table 2: Correlation matrix for the independent variables measuring ballot length and precinct level demographic variables.

\begin{tabular}{|c|c|c|c|c|c|c|c|c|c|c|c|c|}
\hline \multicolumn{13}{|c|}{ Independent Variables } \\
\hline & 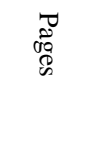 & $\begin{array}{l}\frac{n}{\sigma} \\
\stackrel{\infty}{\infty}\end{array}$ & 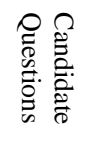 & 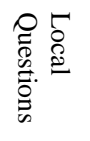 & 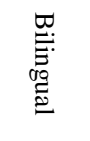 & 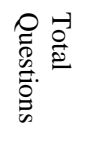 & 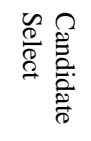 & 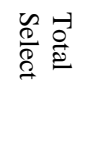 & 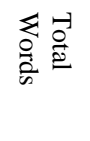 & 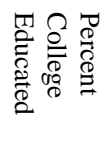 & 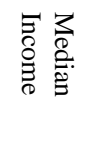 & 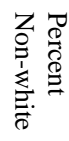 \\
\hline Pages & - & & & & & & & & & & & \\
\hline Sheets & 0.961 & - & & & & & & & & & & \\
\hline $\begin{array}{l}\text { Candidate } \\
\text { Questions }\end{array}$ & 0.059 & 0.040 & - & & & & & & & & & \\
\hline $\begin{array}{l}\text { Local } \\
\text { Questions }\end{array}$ & 0.650 & 0.532 & 0.263 & - & & & & & & & & \\
\hline Bilingual & 0.585 & 0.634 & -0.163 & 0.219 & - & & & & & & & \\
\hline $\begin{array}{l}\text { Total } \\
\text { Questions }\end{array}$ & 0.559 & 0.455 & 0.605 & 0.928 & 0.118 & - & & & & & & \\
\hline $\begin{array}{l}\text { Candidate } \\
\text { Select }\end{array}$ & 0.365 & 0.415 & 0.471 & 0.315 & 0.046 & 0.443 & - & & & & & \\
\hline $\begin{array}{l}\text { Total } \\
\text { Select }\end{array}$ & 0.599 & 0.572 & 0.468 & 0.751 & 0.149 & 0.801 & 0.863 & - & & & & \\
\hline $\begin{array}{l}\text { Total } \\
\text { Words }\end{array}$ & 0.905 & 0.816 & -0.009 & 0.728 & 0.603 & 0.597 & 0.194 & 0.522 & - & & & \\
\hline $\begin{array}{l}\text { Percent } \\
\text { College } \\
\text { Educated }\end{array}$ & -0.337 & -0.375 & -0.099 & -0.124 & -0.283 & -0.140 & 0.026 & -0.048 & -0.285 & - & & \\
\hline $\begin{array}{l}\text { Median } \\
\text { Income }\end{array}$ & -0.248 & -0.284 & 0.097 & -0.019 & -0.492 & 0.022 & 0.105 & 0.063 & -0.231 & 0.683 & - & \\
\hline $\begin{array}{l}\text { Percent } \\
\text { Non-white }\end{array}$ & 0.290 & 0.278 & -0.144 & 0.118 & 0.721 & 0.042 & -0.195 & -0.073 & 0.360 & -0.421 & -0.634 & - \\
\hline
\end{tabular}

All correlations are found to be significant with a p-value $<0.0003$. Bolded observations are considered highly correlated $(>=|0.8|)$. 
To demonstrate which variables are included in each model, Table 3 shows which of the discussed ballot length measurements and demographic variables are in the municipal level and precinct level models. An ' $\mathrm{X}$ ' indicates that the corresponding variable is not included either due to collinearity or inapplicability given the model.

Table 3: Independent variables per model level

\begin{tabular}{ccc}
\hline Independent Variables & Municipal Level & Precinct Level \\
\hline Pages & $\checkmark$ & $\checkmark$ \\
Sheets & X & X \\
Candidate Questions & $\checkmark$ & $\checkmark$ \\
Local Questions & $\checkmark$ & $\checkmark$ \\
Bilingual & X & $\checkmark$ \\
Total Questions & X & X \\
Candidate Select & $\checkmark$ & $\checkmark$ \\
Total Select & X & X \\
Total Words & X & $\checkmark$ \\
Percent College Educated & $\checkmark$ & $\checkmark$ \\
Median Income & $\checkmark$ & X \\
Urbanicity & $\checkmark$ & $\checkmark$ \\
Percent Non-white & $\checkmark$ & $\checkmark$ \\
\hline
\end{tabular}

Note: The checkmark indicates that the variable is included in the model. An ' $\mathrm{X}$ ' indicates it was not included in the model.

Coding of Voting Error Types

In addition to the ballot length measurements, voting errors were defined and categorized. The categorization of error types follows an integrated approach of systems thinking and traditional ergonomics perspective. Errors are classified based on the system elements (i.e., the human and the machine) or their interactions (i.e., human-machine interaction) that cause the error occurrence (Meadows \& Wright, 2015). In order to classify each DS200 error code, the DS200 training manual (Election Systems and Software, 2011, pp. 7-8) and the observation description generated by the scanner log files were considered based on the perspective of occurrence. The categories of 'No 
Error' contains events that did not result in an error of any type (purple highlighted in Figure 1). Any ballot scan that prompted voter interaction with the DS200 beyond the traditional submission process is considered an error due to its potential impact on the voting processes within a polling location (e.g., due to long lines, voter disenfranchisement, distrust in the voting system). Physical errors that occurred while a voter was interacting with the machine are classified as a 'Human-Machine Interaction' (HMI) error, such as "multiple ballots detected" or "ballot was not inserted far enough" (Gautam \& Singh, 2015). Errors that occur due to the programming of the machine or due to the device's functionality are classified as 'Machine' errors (e.g., "ballot jam", "error scanning ballot", "ballot could not be read") (Gautam \& Singh, 2015). The final classification is 'Marking' error which contains events that were caused by inappropriate pen markings made or ballot accepted/rejected by the voters. 'Marking' errors may be caused by creating marks on restricted areas of the ballot (unreadable marks), marking too many selections for a single question (e.g., voter accepted/rejected overvoted ballot), or leaving the ballot blank (e.g., voter accepted/rejected blank ballot) (see Appendix E). From an ergonomics perspective, 'Marking' errors are considered physical or cognitive shortfalls between the voter and the ballot or between the voter and the method of marking.

It is important to note that the 2018 RI Midterm DS200 logs were not programmed to retain information regarding undervotes, thus this error was unable to be included in this study given this dataset. 
Statistical Methods

Two steps were used in performing this analysis: 1) Pearson's correlation tests and 2) logistic regression modeling. The correlation testing was used to select which of the possible ballot length and demographic variables were included in the models. Two logistic regression models (i.e., binary response and multinomial unordered response) are described at two geographic levels (i.e., municipal and precinct) as they were used throughout the analysis of voting error. For each model type at each level of analysis, independent variables and dependent variables are classified.

Pearson's correlation testing was performed within and between all ballot length variables and municipal level demographic variables, as well as within and between all ballot length variables and precinct level demographic variables. Variables were considered highly correlated if their correlation coefficient was equal to or exceeded 0.8 . The maximum alpha value allowed to reject the null hypothesis for the Pearson's correlation test was 0.0003 . This value was adjusted using the Bonferroni correction method with the original alpha being 0.05 and a total of 158 test performed $(0.05 / 158=$ $0.0003)$.

To investigate the relationship between ballot length and voting errors, regression analyses are conducted once the data cleaning and correlation tests were performed. Literature in voting research exploring voting errors has used several forms of regression models to explore independent variable effects on continuous dependent variables (Milita, 2017; Kimball \& Kropf, 2005; Herrnson, Hanmer, \& Niemi, 2012; Hamilton \& Ladd, 1996). In this paper, two approaches are used to measure the response: binary (i.e., no error and error) and categorical (i.e., whether errors occur and what types of errors occur), 
indicating the need for multiple logistic regression models. These models are used strictly to explore the relationship between ballot length metrics and voting errors as they occurred in the 2018 RI Midterm elections at the municipal level and precinct level. This combination of two types of dependent variable classification (i.e., binary and categorical) and geographic level (i.e., municipality and precinct) will result in four logistic regression models and eight unique regression equations with controls for voter demographics.

Each model quantifies the impact of ballot length (i.e., independent variables) on the odds of encountering a voting error (i.e., dependent variable) at different levels of granularity. First, the general models were created considering the dependent variable as a binary response where the occurrence of any type of voting error is considered an event (1) and 'No Error' observations are considered non-events (0). Differentiated models were created representing events in a multinomial, unordered manner where the error types (i.e., 'Machine', and 'Marking', and 'HMI') are treated independently and compared against the non-event (i.e., 'No Error') observations. The two differentiated models each resulted in three regression equations, one for each error type, using the non-event (i.e., 'No Error') observations as a reference model (Wang, 2005). Additional, aggregated voter demographics are controlled for in both models at the municipal level and precinct level.

The general and differentiated models were created in R-Studio using the 'glm' function from the 'stats' package and the 'multinom' function from the 'nnet' package, respectively. The resulting coefficients (i.e., the $\log$ odds) of the multiple logistic regression models are converted into the percent change in the odds of an event (i.e., a voting error) occurring to express the impact of each variable. Variables were considered significant if their p-values exceeded a Bonferroni corrected alpha value of 0.0003 . 
Results

Overview of Voting Error Rates

The error rates observed in the DS200 log files during the 2018 Midterm election in RI are presented in Table 4. While over $90 \%$ of scans resulted in 'No Error', there are relatively large rates of error $(7.06 \%)$ given the context of events. 'Marking' errors are the most frequently occurring of the error types at 4.29\%, with 'HMI' and 'Machine' errors each representing $1.21 \%$ and $1.56 \%$ of the total scanning events, respectively.

Table 4: Overall error rates by error type in the 2018 RI Midterm election

\begin{tabular}{cc}
\hline Error Type & Error Rate \\
\hline HMI & $1.21 \%$ \\
Machine & $1.56 \%$ \\
Marking & $4.29 \%$ \\
No Error & $92.94 \%$ \\
\hline
\end{tabular}

Analysis of the General Models

The general models were applied to the data using the binary response for voting error first analyzing at the municipal level (Table 5) and then at the precinct level (Table 6).

\section{Municipal Level General Model}

Table 5 presents the results of the municipal level general model, indicating the significant ballot length variables as 'Pages' ( $\mathrm{p}$-value = 3.92e-07), 'Local Questions' (pvalue $=4.14 \mathrm{e}-09)$ and 'Candidate Select' $(\mathrm{p}$-value $=0.000)$. 'Pages', 'Local Questions', and 'Candidate Select' in the precinct level general model demonstrate an increase in the odds of error as their metrics increase by one unit, thus an increase of one page increases the odds of an error by $8.590 \%$, an increase of one 'Local Question' increases the odds of an error by $1.609 \%$, whereas an additional 'Candidate Select' opportunity increases the 
odds of error by $2.893 \%$. Of the demographic variables in the municipal level general model, 'Median Income' ( $\mathrm{p}$-value $=1.92 \mathrm{e}-07)$ and 'Urbanicity' $(\mathrm{p}$-value $=8.08 \mathrm{e}-10)$ are significant. The results show that as 'Median Income' increases by one dollar, the odds of error are reduced by $0.0005 \%$. As 'Urbanicity' is increased by one percent, the odds of error are increased by $26.838 \%$. The remaining ballot length variable 'Candidate Questions' and the remaining municipal level demographic variables 'Percent College Educated' and 'Percent Non-white' are not significant in the municipal level general model.

Table 5: Municipal level general model results

\begin{tabular}{|c|c|c|c|c|c|c|}
\hline Variable & $\begin{array}{l}\text { Coefficient } \\
\text { Estimate }\end{array}$ & $\begin{array}{c}\text { Percent } \\
\text { Change in } \\
\text { Odds }\end{array}$ & $\begin{array}{l}\text { Standard } \\
\text { Error }\end{array}$ & $Z$ value & \multicolumn{2}{|c|}{ p-value } \\
\hline Intercept & -2.998 & -95.010 & 0.104 & -28.756 & 0.000 & $* * *$ \\
\hline Pages & 0.082 & 8.590 & 0.016 & 5.073 & $3.92 \mathrm{e}-07$ & $* * *$ \\
\hline $\begin{array}{l}\text { Candidate } \\
\text { Questions }\end{array}$ & 0.004 & -0.418 & 0.005 & -0.772 & 0.440 & \\
\hline Local Questions & 0.016 & 1.609 & 0.003 & 5.878 & $4.14 \mathrm{e}-09$ & $* * *$ \\
\hline Candidate Select & 0.029 & 2.893 & 0.002 & 13.114 & 0.000 & $* * *$ \\
\hline $\begin{array}{l}\text { Percent College } \\
\text { Educated }\end{array}$ & -0.004 & -0.396 & 0.001 & -3.404 & $6.63 e-4$ & \\
\hline Median Income & $-5.04 \mathrm{e}-06$ & $-5.04 e-04$ & $9.67 \mathrm{e}-07$ & -5.207 & $1.92 \mathrm{e}-07$ & $* * *$ \\
\hline Urbanicity & 0.238 & 26.838 & 0.039 & 6.143 & $8.08 \mathrm{e}-10$ & $* * *$ \\
\hline Percent Non-white & 0.000 & 0.025 & 0.001 & 0.310 & 0.757 & \\
\hline
\end{tabular}

The results of both the municipal level and precinct level general models are used to test hypotheses $\mathrm{H} 1$ independently. In the municipal level general model, the ballot length variables 'Pages', ‘Local Questions', and 'Candidate Select' reject the null hypothesis (i.e., increasing measures of ballot length increase the odds of voting errors). The remaining ballot length variable in the model (i.e., 'Candidate Questions') fails to reject the null 
hypothesis as it demonstrates no significant impact on the odds of voting errors at the municipal level.

\section{Precinct Level General Model}

Table 6 presents the results of the precinct level general model, indicating the significant ballot length variables are 'Candidate Questions' ( $p$-value $=2.28 \mathrm{e}-04)$, 'Local Questions' $(\mathrm{p}$-value $=0.000)$, 'Bilingual' $(\mathrm{p}$-value $=1.34 \mathrm{e}-05)$, and 'Candidate Select' $(\mathrm{p}$ value $=0.000)$. The significant ballot length variables, aside from 'Candidate Questions', demonstrate an increase in the odds of error as their metrics increase by one unit. The variable 'Candidate Questions' demonstrates a decrease in the odds of error as its measure increases by one unit. As the number of candidate question increases by one, the odds of an error decrease by $1.898 \%$. An increase of one local question increases the odds of an error by $2.024 \%$. A ballot that is distributed in a 'Bilingual' format increases the odds of error by $12.114 \%$. An additional 'Candidate Select' opportunity increases the odds of error by $2.932 \%$. Of the demographic variables in the precinct level general model, 'Percent College Educated' (p-value $=0.000)$ and 'Median Income' (p-value = 0.000) are significant. The results show that as 'Percent College Educated' increases by one unit, the odds of error are reduced by $0.886 \%$. As 'Median Income' is increased by one dollar, the odds of error are increased by $0.00015 \%$. The remaining variables 'Pages' and 'Percent Non-white' are not significant in the precinct level general model. 
Table 6: Precinct level general model results

\begin{tabular}{|c|c|c|c|c|c|c|}
\hline Variable & $\begin{array}{c}\text { Coefficient } \\
\text { Estimate }\end{array}$ & $\begin{array}{l}\text { Percent } \\
\text { Change in } \\
\text { Odds }\end{array}$ & $\begin{array}{c}\text { Standard } \\
\text { Error }\end{array}$ & $Z$ value & \multicolumn{2}{|c|}{ p-value } \\
\hline Intercept & -2.892 & -94.451 & 0.075 & -38.489 & 0.000 & $* * *$ \\
\hline Pages & 0.036 & 3.416 & 0.016 & 2.081 & 0.037 & \\
\hline $\begin{array}{l}\text { Candidate } \\
\text { Questions }\end{array}$ & -0.019 & -1.898 & 0.005 & -3.685 & $2.28 \mathrm{e}-04$ & $*$ \\
\hline Local Questions & 0.020 & 2.024 & 0.003 & 7.413 & 0.000 & $* * *$ \\
\hline Bilingual & 0.114 & 12.114 & 0.026 & 4.354 & $1.34 \mathrm{e}-05$ & $* * *$ \\
\hline Candidate Select & 0.020 & 2.932 & 0.002 & 14.836 & 0.000 & $* *$ \\
\hline $\begin{array}{l}\text { Percent College } \\
\text { Educated }\end{array}$ & -0.009 & -0.886 & 0.001 & -14.616 & 0.000 & $* * *$ \\
\hline Median Income & $1.54 \mathrm{e}-06$ & $1.54 \mathrm{e}-04$ & $5.02 \mathrm{e}-07$ & 3.063 & 0.000 & $* * *$ \\
\hline Percent Non-white & 0.006 & 0.583 & 0.001 & 9.357 & 0.002 & \\
\hline
\end{tabular}

Significance Codes: p-value $<0.0003$ ('*’); p-value $<0.00006$ ('**'); p-value $<0.000006$ ('***’) (Bonferroni corrected)

At the precinct level, hypothesis $H 1$ is tested for all ballot length variables. The significant ballot length variables 'Local Questions', 'Bilingual', and 'Candidate Select' reject the null hypothesis as an increase of one unit in each measure increases the odds of experiencing voting errors (Table 6). The variables 'Pages' and 'Candidate Questions' fail to reject the null hypothesis, as 'Pages' demonstrates no significant impact on the odds of voting error and 'Candidate Questions' reduces the odds of error as its measure increases.

Analysis of the Differentiated Model

Within the differentiated models, effects are separated by error type (i.e., Marking, Machine, and HMI) with the 'No Error' observations as a reference event. Table 7 and 
Table 9 present the results of the differentiated model at the municipal level and the results of the precinct level, respectively.

\section{Municipal Level Differentiated Model}

The municipal level differentiated model, shown in Table 7, identifies that all ballot length variables and municipal level demographic variables significantly impact the odds of 'HMI' errors occurring (all p-values $=0.000$ ). Of the ballot length variables, an increase of one page increases the odds of 'HMI' errors by $160.862 \%$, an additional candidate-based question reduces the odds of 'HMI' errors by $0.773 \%$, an additional local question reduces the odds of 'HMI' errors by $7.087 \%$, and an additional 'Candidate Select' opportunity increases the odds of 'HMI' errors by $2.832 \%$. Of the municipal level demographic variables, an increase in the 'Percent College Educated' of one percent increases the odds of 'HMI' errors by $0.214 \%$, an increase in 'Median Income' of one dollar reduces the odds of 'HMI' errors by $0.001 \%$, an increase in 'Urbanicity' of one percent increases the odds of 'HMI' errors by $36.680 \%$, and an increase in 'Percent Non-white' of one percent reduces the odds of 'HMI' errors by $1.321 \%$.

The municipal level differentiated model results indicate that all ballot length variables significantly impact 'Machine' errors (all with p-value $=0.000$ ). Of these variables, an increase of one page reduces the odds of 'Machine' errors by 5.261\%, an increase of one candidate-based question increases the odds of 'Machine' errors by $4.501 \%$, an increase of one local question increases the odds of 'Machine' errors by $4.440 \%$, and an increase of one 'Candidate Select' opportunity reduces the odds of 'Machine' errors by $6.669 \%$. Of the municipal level demographic variables, 'Percent College Educated', 'Median Income', and 'Urbanicity' are significant with equal p-values of 0.000 . The demographic variable 
'Percent Non-white' is not significant in the model $(\mathrm{p}$-value $=3.82 \mathrm{e}-04)$. The model identifies that an increase in 'Percent College Educated' by one percent increases the odds of 'Machine' errors by $1.343 \%$, an increase in 'Median Income' of one dollar decreases the odds of 'Machine' error by $0.00078 \%$, and an increase in 'Urbanicity' of one percent increases the odds of 'Machine' errors by $0.147 \%$.

Within the municipal level differentiated model, the odds of 'Marking' errors occurring are significantly impacted by all ballot length variables with equal p-values of 0.000 . Within this regression, an increase of one page reduces the odds of 'Marking' errors by 9.462\%, an increase of one candidate-based question reduces the odds of 'Marking' errors by $1.532 \%$, an increase of one local question increases the odds of 'Marking' errors by 2.747\%, and an additional 'Candidate Select' opportunity increases the odds of 'Marking' errors by $5.456 \%$. Of the municipal level demographic variables included in this differentiated model, the variables 'Percent College Educated', 'Median Income', 'Urbanicity', and 'Percent Non-white' are all significant with p-values of 0.000. An increase in 'Percent College Educated' by one percent reduces the odds of 'Marking' errors by $0.882 \%$, an increase in 'Median Income' of one dollar reduces the odds of 'Marking' errors by $0.000025 \%$, an increase in 'Urbanicity' of one percent increases the odds of 'Marking' errors by $24.853 \%$, and an increase in 'Percent Non-white' of one percent increases the odds of 'Marking' errors by $0.371 \%$. 
Table 7: Municipal level differentiated model results.

\begin{tabular}{|c|c|c|c|c|c|c|c|c|c|}
\hline \multirow{3}{*}{$\begin{array}{l}\text { Variable } \\
\text { Intercept }\end{array}$} & \multicolumn{3}{|c|}{ HMI Error } & \multicolumn{3}{|c|}{ Machine Error } & \multicolumn{3}{|c|}{ Marking Error } \\
\hline & \multirow{2}{*}{$\begin{array}{c}\begin{array}{c}\text { Percent } \\
\text { Change in } \\
\text { Odds }\end{array} \\
-99.785 \\
\end{array}$} & \multicolumn{2}{|c|}{ p-value } & \multirow{2}{*}{$\begin{array}{c}\begin{array}{c}\text { Percent } \\
\text { Change in } \\
\text { Odds }\end{array} \\
-96.706\end{array}$} & \multicolumn{2}{|c|}{ p-value } & \multirow{2}{*}{$\begin{array}{c}\begin{array}{c}\text { Percent } \\
\text { Change in } \\
\text { Odds }\end{array} \\
-96.720\end{array}$} & \multicolumn{2}{|c|}{ p-value } \\
\hline & & 0.000 & $* * *$ & & 0.000 & $* * *$ & & 0.000 & $* * *$ \\
\hline Pages & 160.862 & 0.000 & $* * *$ & -5.261 & 0.000 & $* * *$ & -9.462 & 0.000 & $* * *$ \\
\hline $\begin{array}{l}\text { Candidate } \\
\text { Questions }\end{array}$ & -0.773 & 0.000 & $* * *$ & 4.501 & 0.000 & $* * *$ & -1.532 & 0.000 & $* * *$ \\
\hline Local Questions & -7.087 & 0.000 & $* * *$ & 4.440 & 0.000 & $* * *$ & 2.747 & 0.000 & $* * *$ \\
\hline Candidate Select & 2.832 & 0.000 & $* * *$ & -6.669 & 0.000 & $* * *$ & 5.456 & 0.000 & $* * *$ \\
\hline $\begin{array}{l}\text { Percent College } \\
\text { Educated }\end{array}$ & 0.214 & 0.000 & $* * *$ & 1.343 & 0.000 & $* * *$ & -0.882 & 0.000 & $* * *$ \\
\hline Median Income & -0.001 & 0.000 & $* * *$ & $-7.80 \mathrm{e}-04$ & 0.000 & $* * *$ & $-2.50 e-5$ & 0.000 & $* * *$ \\
\hline Urbanicity & 36.680 & 0.000 & $* * *$ & 0.147 & 0.000 & $* * *$ & 24.853 & 0.000 & $* * *$ \\
\hline $\begin{array}{l}\text { Percent Non- } \\
\text { white }\end{array}$ & -1.321 & 0.000 & $* * *$ & -0.219 & $3.82 \mathrm{e}-04$ & & 0.371 & 0.000 & $* * *$ \\
\hline
\end{tabular}

Hypothesis $H 1$ is assessed for the municipal level differentiated model. Within each error type's regression in this model, $H 1$ is assessed by variable, as no regression demonstrates a unanimous increase in the odds of voting errors with an increase in ballot length. Table 8 displays the direction of the impact on the odds of error for each regression within the municipal level differentiated model. 
Table 8: Directionality of municipal level differentiated model effects.

\begin{tabular}{|c|c|c|c|}
\hline Variable & HMI & Machine & Marking \\
\hline Intercept & - & - & - \\
\hline Pages & + & - & - \\
\hline Candidate Questions & - & + & - \\
\hline Local Questions & - & + & + \\
\hline Candidate Select & + & - & + \\
\hline $\begin{array}{c}\text { Percent College } \\
\text { Educated }\end{array}$ & + & + & - \\
\hline Median Income & - & - & - \\
\hline Urbanicity & + & + & + \\
\hline Percent Non-white & - & N/A & + \\
\hline
\end{tabular}

Note: (+) increase in the odds of error, (-) decrease in the odds of error, (N/A) variable not significant.

With respect to 'HMI' errors, the variables 'Pages' and 'Candidate Select' reject the null hypothesis, as they increase the odds of 'HMI' errors when each variable's value increases. The variables 'Candidate Questions' and 'Local Questions' fail to reject the null hypothesis as they do not increase the odds of 'HMI' errors as their values increase.

For 'Machine' errors in the municipal level differentiated model, the null hypothesis is rejected for the variables 'Candidate Questions' and 'Local Questions'. The ballot length variables 'Pages' and 'Candidate Select' fail to reject the null hypothesis as they decrease the odds of error as their values increase.

Within the 'Marking' error regression, the ballot length variables 'Local Questions' and 'Candidate Select' reject the null hypothesis due to their increase in the odds of 'Marking' errors as their values increase. The variables 'Pages' and 'Candidate Questions' fail to reject the null hypothesis due to their decrease in the odds of 'Marking' errors as their values increase. 


\section{Precinct Level Differentiated Model}

The precinct level differentiated model shown in Table 9 identifies the impact of ballot length and precinct level demographics on 'HMI', 'Machine', and 'Marking' errors, independently.

With respect to 'HMI' errors in the precinct level differentiated model, all ballot length variables are significant ( $\mathrm{p}$-values $=0.000)$. Of the significant ballot length variables, an increase of one page increases the odds of 'HMI' errors by $125.650 \%$, an increase of one candidate-based question reduces the odds of 'HMI' errors by $4.676 \%$, an additional local question reduces the odds of 'HMI' errors by $6.293 \%$, a 'Bilingual' formatted ballot increases the odds of 'HMI' errors by $26.954 \%$, and an increase of one 'Candidate Select' opportunity increases the odds of 'HMI' errors by $3.346 \%$. Of the significant precinct level demographic variables, an increase in 'Percent College Educated' of one percent reduces the odds of 'HMI' errors by $1.299 \%$, an increase in 'Median Income' of one dollar increases the odds of 'HMI' errors by $0.000198 \%$, and an increase in 'Percent Non-white' of one percent reduces the odds of 'HMI' errors by $0.342 \%$.

With respect to 'Machine' errors, the precinct level differentiated model indicates that all ballot length variables are significant $(\mathrm{p}$-values $=0.000)$. Of the significant ballot length variables, an increase of one page reduces the odds of 'Machine' errors by $16.067 \%$, an increase of one candidate-based question increases the odds of 'Machine' errors by $0.588 \%$, an increase of one local question increases the odds of 'Machine' errors by $5.003 \%$, a 'Bilingual' formatted ballot reduces the odds of 'Machine' errors by $6.698 \%$, and an additional 'Candidate Select' opportunity reduces the odds of 'Machine' errors by 4.696\%. Of the included precinct level demographic variables, 'Percent College Educated' 
and 'Percent Non-white' are significant with equal p-values of 0.000 and 'Median Income' is significant with a p-value of 5.66e-08. As demonstrated in Table 9, an increase in 'Percent College Educated' of one percent reduces the odds of 'Machine' errors by $0.263 \%$, an increase in 'Median Income' of one dollar increases the odds of 'Machine' errors by $0.000129 \%$, and an increase in 'Percent Non-white' of one percent increases the odds of 'Machine' errors by $0.681 \%$.

Investigating 'Marking' errors in the precinct level differentiated model indicates that all ballot length variables are significant in the model ( $\mathrm{p}$-values $=0.000$ ). Among the significant ballot length variables, an increase of one page reduces the odds of 'Marking' errors by $7.220 \%$, an increase of one candidate-based question reduces the odds of 'Marking' errors by $3.226 \%$, an increase of one local question increases the odds of 'Marking' errors by $2.718 \%$, a 'Bilingual' formatted ballot reduces the odds of 'Marking' errors by $2.401 \%$, and an additional 'Candidate Select' opportunity increases the odds of 'Marking' errors by $5.620 \%$. Of the precinct level demographic variables, all but 'Median Income' are significant with p-values of 0.000. An increase in 'Percent College Educated' of one percent reduces the odds of 'Marking' errors by $0.926 \%$, an increase in 'Percent Non-white' of one percent increases the odds of 'Marking' errors by $1.027 \%$. 
Table 9: Precinct level differentiated model results.

\begin{tabular}{|c|c|c|c|c|c|c|c|c|c|}
\hline & \multicolumn{3}{|c|}{ HMI Error } & \multicolumn{3}{|c|}{ Machine Error } & \multicolumn{3}{|c|}{ Marking Error } \\
\hline \multirow{2}{*}{$\begin{array}{l}\text { Variable } \\
\text { Intercept }\end{array}$} & \multirow{2}{*}{$\begin{array}{c}\begin{array}{c}\text { Percent } \\
\text { Change in } \\
\text { Odds }\end{array} \\
-99.739\end{array}$} & \multicolumn{2}{|c|}{ p-value } & \multirow{2}{*}{$\begin{array}{c}\text { Percent } \\
\text { Change } \\
\text { in Odds } \\
-95.879\end{array}$} & \multicolumn{2}{|c|}{ p-value } & \multirow{2}{*}{$\begin{array}{c}\text { Percent } \\
\text { Change } \\
\text { in Odds } \\
-96.708\end{array}$} & \multicolumn{2}{|c|}{ p-value } \\
\hline & & 0.000 & $* * *$ & & 0.000 & $* * *$ & & 0.000 & $* * *$ \\
\hline Pages & 125.650 & 0.000 & $* * *$ & -16.067 & 0.000 & $* * *$ & -7.220 & 0.000 & $* * *$ \\
\hline $\begin{array}{l}\text { Candidate } \\
\text { Questions }\end{array}$ & -4.676 & 0.000 & $* * *$ & 0.588 & 0.000 & $* * *$ & -3.226 & 0.000 & $* * *$ \\
\hline Local Questions & -6.293 & 0.000 & $* * *$ & 5.003 & 0.000 & $* * *$ & 2.718 & 0.000 & $* * *$ \\
\hline Bilingual & 26.954 & 0.000 & $* * *$ & -6.698 & 0.000 & $* * *$ & -2.401 & 0.000 & $* * *$ \\
\hline Candidate Select & 3.346 & 0.000 & $* * *$ & -4.696 & 0.000 & $* * *$ & 5.620 & 0.000 & $* * *$ \\
\hline $\begin{array}{l}\text { Percent College } \\
\text { Educated }\end{array}$ & -1.299 & 0.000 & $* * *$ & -0.263 & 0.000 & $* * *$ & -0.926 & 0.000 & $* * *$ \\
\hline Median Income & $1.98 \mathrm{e}-4$ & $1.56 \mathrm{e}-10$ & $* * *$ & $1.29 \mathrm{e}-4$ & $5.66 \mathrm{e}-08$ & $* * *$ & $1.20 \mathrm{e}-4$ & 0.002 & \\
\hline $\begin{array}{l}\text { Percent Non- } \\
\text { white }\end{array}$ & -0.342 & $8.76 \mathrm{e}-09$ & $* * *$ & 0.681 & 0.000 & $* * *$ & 1.027 & 0.000 & $* * *$ \\
\hline
\end{tabular}

Within each error type's regression in the precinct level differentiated model, $\mathrm{Hl}$ is assessed per variable, as no regression demonstrates a unanimous increase in the odds of voting errors with an increase in ballot length. Table 10 displays the direction of the impact on the odds of error for each regression within the model. 
Table 10: Directionality of precinct level differentiated model effects.

\begin{tabular}{cccc}
\hline Variable & HMI & Machine & Marking \\
\hline Intercept & - & - & - \\
Pages & + & - & - \\
Candidate Questions & - & + & - \\
Local Questions & - & + & - \\
Bilingual & + & - & + \\
Candidate Select & + & - & - \\
Percent College & - & - & N/A \\
Educated & - & + & + \\
Median Income & + & + & error
\end{tabular}

Note: (+) increase in the odds of error, (-) decrease in the odds of error, (N/A) variable not significant.

The variables 'Pages', 'Bilingual', and 'Candidate Select' reject the null hypothesis for the 'HMI' error regression. The variables 'Candidate Questions' and 'Local Questions' fail to reject the null hypothesis for the 'HMI' regression as an increase in their measure demonstrated a decrease in the odds of 'HMI' errors.

Within the 'Machine' error regression, the variables 'Candidate Questions' and 'Local Questions' reject the null hypothesis. For each of these variables, an increase in their measure results in an increase in the odds of 'Machine' errors. The variables 'Pages', 'Bilingual', and 'Candidate Select' fail to reject the null hypothesis.

Within the 'Marking' error regression, the variables 'Local Questions' and 'Candidate Select' reject the null hypothesis. The variables 'Pages', 'Candidate Questions', and 'Bilingual' fail to reject the null hypothesis for the 'Marking' regression in the precinct level differentiated model. 


\section{Discussion}

Measures of ballot length impact specific types of voting errors (i.e., HMI, Machine, Marking), although the directionality and magnitude of these effects vary. These findings agree with the general implication of Selb (2008) which indicate that ballot length impacts voting systems. While research question one $(R l)$ is answered, that ballot length does indeed impact voting errors, research question two $(R 2)$ must be addressed per model (i.e., the general model and differentiated model) at both the municipal and precinct levels.

The findings that some elements of ballot length increase the odds of voting error are consistent, providing insight into answering research question $R l$. These models demonstrate that ballot length does impact the odds of experiencing voting errors. Additionally, the directionality and magnitude of ballot length effects are determined from a general perspective, thus partially addressing research question $R 2$. However, there are differences between the municipal level and precinct level general models regarding these impact magnitudes and direction. Where the models agree is in their significance and direction of some demographic variables. This indicates that, in general, areas with demographics that corresponded with commonly under-resourced communities (i.e., low percent college educated, low median income, and high urbanicity) experienced more voting errors regardless of ballot length during the 2018 RI Midterm election. With this information, resource allocation by election officials can be adjusted to provide additional personnel and equipment to municipalities that might require it in future elections.

With respect to ballot length, the municipal level general model results specifically indicate that increases in 'Pages', 'Local Questions', and/or 'Candidate Select' opportunities increase the odds of voting errors. Considering the error rates in Table 4, 
approximately $7.06 \%$ of scans in RI contained an error. The municipal level general model implies that the addition of a single ballot page across RI would increase the odds of voting errors by $8.590 \%$, indicating an increase in error rate to $7.666 \%$. The impact on the odds of voting errors in the municipal level general model from 'Urbanicity' would increase the error rate from $7.06 \%$ to $8.955 \%$ with an additional 'Urbanicity' percentage point. This model suggests that municipalities that have highly populated urban areas and municipalities that distributed longer ballots, with respect to the number of pages, local questions, and candidate selections, experienced significantly higher odds of voting errors during the 2018 RI Midterm election. Considering this investigation focused on a RI election, the high population density of the state may explain the large impact of 'Urbanicity'. With up to 3,000 voters assigned to a single polling location in RI, areas that are more densely populated/have higher 'Urbanicity' experience more heavily used equipment and more opportunities for error (i.e., more users of the system). To avoid potential delays caused by these errors in future elections, additional resources (i.e., poll workers and voting equipment) may be allocated to municipalities with long ballots and high urbanicity. However, future research should explore whether urbanicity is truly a function of population density when investigating voting error or if the impact is caused by the number of voters per piece of voting equipment. In order to explore urbanicity more in depth, cross-state and cross-election investigations must be performed.

The issue with this recommendation becomes that the overall capacity and layout planning that is or is not able to accommodate increases in resource allocation. As more poll workers and more voting equipment are allocated to a municipality, additional physical space is required which, in turn, could require more polling locations within a municipality. 
Locating available space for more polling locations within urban areas continues to be a challenge that confronts election officials across the U.S. with various options being electronic voting (i.e., eliminating polling locations all together, which continues to be a very unpopular idea), voting centers (i.e., central, larger locations where resources can be vast and effectively used while serving larger active voter populations), vote by mail, or even universal polling locations in which any voter can cast a ballot at any polling location within a particular state. Essentially, this has a two-fold meaning. First, that using 'Rules of Thumb' that are developed statewide are not applicable to every municipality or precinct and models that decisions are being made from must continue to consider all variables together in a robust manner in a continuous improvement perspective. And second, that data from technology can be utilized as valuable inputs into these decision-making processes and resource allocation models to eliminate the need for ineffective proxies of polling place performance and resource needs.

An interesting component of this outcome is the fact that these are errors at only one station of the voting system on a specific type of voting equipment (i.e., digital ballot scanners). There are multitudes of opportunities to use data to directly feed into the decision-making loop to continuously improve the models through every election in order to advance these models, such as incorporating data generated by electronic poll books or DREs. Additional research must explore resource allocation models and their current effectiveness, as well as the impact of incorporating other input variables, such as those described in this research, based on reducing errors.

Within the precinct level general model, the ballot length variables 'Local Questions' and 'Candidate Select' increase the odds of voting errors as their measures increase. 
Additionally, 'Bilingual' ballots led to higher odds of error than single language ballots. The 'Local Questions' and 'Candidate Select' variables represent opportunities for voters to mark the ballot. As more voter interaction is required with the ballot, the odds that an error will occur are expected to increase. Interestingly in this model, despite controlling for the non-white population, 'Bilingual' ballots have a large impact on the odds of voting errors by a $12.114 \%$ increase. Bilingual ballots (Appendix B), on average, tend to be quite long by several measures of ballot length when compared to single language ballots. In the 2018 RI Midterm election, the average number of words on a bilingual ballot was 1942 compared to the average number of words on a single language ballot of 860. Additionally, the average number of pages for bilingual ballots was 2.98 compared to an average of 2.07 pages for single language ballots. These longer ballot properties that are associated with bilingual ballots may have caused the increased odds of errors during the 2018 RI Midterm election. Additionally, bilingual ballots are distributed in areas with higher non-English speaking populations. This may indicate a population that is less experienced with the voting process, which may also lead to increased odds of voting errors.

Other potential reasons for the impact of bilingual ballots could be the translation accuracy, the complex and legalese language use in many ballot measures and this interaction with non-English languages, or education about bilingual ballots in general. The impact of bilingual ballots on voting errors presents a critical point of focus as bilingual and multilingual ballots are mandated by law. If more municipalities begin to exceed the threshold for single language ballots, then these errors have the potential to propagate and lead to more serious issues; though, not necessarily due to multilingual ballots themselves, but the properties that are associated with them. Within ballot design research, focusses 
have been on the format of a ballot (e.g., selection method, paper ballot, digital ballot) (Hamilton \& Ladd, 1996; Everett, Byrne, \& Greene, 2006), the layout of the ballot (e.g., the order of candidates, the order of questions, where instructions are on the page) (Kimball \& Kropf, 2003; Kimball \& Kropf, 2005), and the design of the ballot (e.g., bolding of words, language complexity) (Redish, Chisnell, Laskowski, \& Lowry, 2010). The results of the precinct level general model indicate the need to also focus on methods of presenting information in multiple languages, such as using bilingual ballots and facsimile ballots, to determine which formats mitigate effects on voting error rates.

At the precinct level, the length of the ballot significantly increased the odds of voting errors after controlling for precinct level demographics during the 2018 RI Midterm election. With this information, precincts that distribute longer ballots, with respect to the number of 'Local Questions' and 'Candidate Select' opportunities as well as ballots in a 'Bilingual' format may consider performing narrower investigations into the design of ballots. Techniques for survey design may be a helpful resource to accommodate the large amount of information often presented on Midterm and General election ballots. Additional resource allocation techniques may be required that consider traditionally unincluded factors or that more scientifically assess the traditionally included factors. Another component that must be considered is the level of experience that voters have with elections, in general, as well as with a specific ballot design/format or voting equipment.

Assessing both the municipal level and precinct level differentiated models generates insight regarding research questions $R l$. The general models' findings: ballot length does significantly impact the odds of experiencing voting errors. The differentiated models also provide more specific answers to research question $R 2$ : depending on the error type and 
the measure of ballot length, the odds of voting errors may be increased or decreased. Comparing the municipal level and precinct level differentiated models indicates that the odds of 'HMI' errors are consistently increased by measures of ballot length (i.e., the number of pages and the number of candidate select opportunities). Additionally, the municipal level model indicates that 'Urbanicity' contributes to increases in voting errors of all types. In both models, as certain measures of ballot length increase, the odds of experiencing errors are reduced. These effects may be explained by external variables (e.g., voter behavior, level of voting experience, equipment maintenance frequency, other unincluded demographic data).

Within the municipal level differentiated model, error types (i.e., 'HMI', 'Machine', and 'Marking') are investigated independently while controlling for municipal level demographics. The model identifies that the odds of 'HMI' errors are increased by increases in 'Pages' (a 160.862\% increase in the odds of 'HMI' error), 'Candidate Select' opportunities (a $2.832 \%$ increase in the odds of 'HMI' error), and 'Urbanicity' (a 36.680\% increase in the odds of 'HMI' error). In other words, areas that distributed ballots with several pages, more candidate selection opportunities, and/or had high urbanicity experienced more errors when voters attempted to insert their ballot into the DS200. Assessing this impact in terms of the overall 2018 RI Midterm election, the experienced 'HMI' error rate (i.e., 1.21\%) (Table 4) would increase to $3.16 \%$, more than doubling the number of affected voters, if an additional page is added to each ballot. With a single additional percentage point of 'Urbanicity', the state wide 'HMI' error rate would increase from $1.21 \%$ to $1.65 \%$. 'Local Questions' also has a large impact on 'HMI' errors, reducing their odds by $7.087 \%$ when an additional 'Local Questions' is listed on the ballot. On its 
own, there is not much meaning behind this effect, although municipalities that distributed ballots with many local questions during the 2018 RI Midterm election may have shared a trait that confounds the 'Local Questions' variable (e.g., a more voting involved/experienced population).

These findings indicate that the number of ballot pages and the urbanicity of an area impact the odds of 'HMI' errors and therefore require special consideration when preparing for elections. This impact on 'HMI' error may indicate insufficient voter education materials regarding how to use the ballot scanner. Studies can be conducted in areas that have high rates of 'HMI' errors and areas that have several ballot pages and high urbanicity to better understand their underlying relationship. Feedback from voters may also provide insight into why these errors occur.

With respect to 'Machine' errors in the municipal level differentiated model, 'Candidate Questions' and 'Local Questions' have the largest impacts (a 4.501\% increase and $4.440 \%$ increase, respectively). In addition to ballot length, all municipal level demographics, excluding 'Percent Non-white', present significant impacts on the odds of 'Machine' errors. These finding indicate the need to investigate the ballot scanners in active use during real elections. There may be issues with equipment maintenance or an inherent sensitivity to longer ballots that lead to 'Machine' errors. In depth testing of these devices should be performed and compared to test results reported by device manufacturers as well as testing facilities employed by the U.S. Election Assistance Commission. Other investigation should be performed to compare the equipment distributed to different types of areas throughout a region to ensure that the level of maintenance and accuracy of the devices is consistent regardless of area specific demographics. 
Within the 'Marking' error regression, the ballot length variables 'Local Questions' and 'Candidate Select' increase the odds of 'Marking' errors as their measures increase. However, increases in 'Pages' and 'Candidate Questions' significantly reduce the odds of 'Marking' errors. Within this model, 'Urbanicity' increases the odds of 'Marking' errors by $24.853 \%$ as 'Urbanicity' increases by one percentage point. The increase in the odds of 'Marking' errors due to 'Local Questions' and 'Candidate Select' indicates that as voters interact with a ballot more, their odds of mismarking a ballot increase. Additional causes may be from confusion with the wording of local questions, which often include more legalese than candidate questions (Reilly \& Richey, 2011; Milita, 2017), and/or from confusion from the instructions for multiselect candidate questions. Within several candidate-based questions on a ballot, the voter can select more than one candidate whereas on other candidate-based and local questions, marking more than one selection is considered an error. This contradictory instruction may be a source of confusion for voters. Additional research can assist with identifying specific sources of 'Marking' error. This error type is one of the most concerning as it implies the possibility that voters are not able to accurately portray their intentions on the ballot (Redish, Chisnell, Laskowski, \& Lowry, 2010; Herrnson, Hanmer, \& Niemi, 2012).

The municipal level differentiated model demonstrates that variables impacted different types of errors uniquely. The model indicates that municipalities with several pages and municipalities with a large percent of the population living in urban areas experienced higher odds of encountering 'HMI' errors during the 2018 RI Midterm election. The effects of these variables may indicate a need for revised resource allocation techniques and voter education materials to ensure that areas with several page ballots and higher urbanicity can 
cast votes as equally as other areas. 'Machine' errors were more likely to occur in areas with more ballot questions as well as areas with lower median incomes. These findings may indicate that additional maintenance and testing methods for voting equipment may be required for areas distributing longer ballots or in low income regions. Within the 'Marking' error regression, demographic variables such as 'Urbanicity' and 'Median Income' significantly impacted the odds of experiencing 'Marking' errors during the 2018 RI Midterm election as well as the number of 'Local Questions' and 'Candidate Select' opportunities. These factors indicate that more research should be performed on the effectiveness of voter education materials and the instructions provided on the ballot itself. Other research may be performed on the level of assistance that is provided to voters that may not understand how to properly mark a ballot or to investigate how often voters seek assistance when marking a ballot.

Within the precinct level differentiated model, error types (i.e., 'HMI', 'Machine', and 'Marking') are investigated independently while controlling for precinct level demographics. The model identifies that 'HMI' errors are increased by 'Pages' (a $125.650 \%$ increase in the odds of 'HMI' error), the 'Bilingual' ballot format (a 26.954\% increase in the odds of 'HMI' error), and 'Candidate Select' opportunities (a 3.346\% increase in the odds of 'HMI' error). As the number of ballot pages increase, voters must feed additional ballot sheets into the scanner, providing more opportunities to incorrectly insert the ballot. 'Bilingual' ballots also cause several ballot length measurements to increase (i.e., questions are listed once in English and once in Spanish in the case of RI) potentially leading to additional opportunities for 'HMI' errors. Assessing this impact with 
respect to $2018 \mathrm{RI}$ Midterm error rates, presented in Table 4, the 1.21\% statewide 'HMI' error rate would increase to $2.73 \%$ if an additional page is added to each distributed ballot.

These impacts on the odds of 'HMI' errors indicates the tradeoff between longer ballots and the rate of 'HMI' error. Despite longer ballots allowing for increased voter participation, more voting errors may occur. While 'HMI' errors can be resolved by either reinserting the ballot or remarking a new ballot, there is still the potential to disenfranchise the voter and cause delays or lines in a polling location. Additional research is required to determine the effectiveness of distributed instructions regarding how to properly scan a ballot. During the 2018 RI Midterm elections, additional personnel was stationed at the ballot scanning station in every precinct, however these errors are still present indicating that voters may not be seeking help.

All ballot length variables also significantly impacted the odds of 'Machine' errors, however only the variable 'Local Questions' largely increased the odds of 'Machine' errors (a $5.003 \%$ increase). Considering the results of the precinct level differentiated model, there may be an element of the scanning process that is uncaptured in the model, such as the general capabilities of the DS200.

The 'Marking' error regression in the precinct level differentiated model indicated that 'Local Questions', 'Candidate Select' opportunities, and 'Percent Non-white' significantly increased the odds of 'Marking' errors as their measures increase, agreeing with the findings of the municipal level differentiated model. An interesting finding in this model is that 'Bilingual' formatted ballots led to a decrease in the odds of 'Marking' errors by $2.401 \%$, demonstrating the benefit of language accessible ballots. This effect of bilingual ballots further indicates that additional research should investigate their design and use in 
elections. While their importance in the democratic process is clear, there may be unnoticed complications with the current methods of designing and/or implementing language accessible ballots. A study into the format, design, and translation accuracy of bilingual and multilingual ballots can provide insight into how to better accommodate low English proficiency voters, as well as mitigate any effect these ballots may have on voting errors in general.

The results of the precinct level differentiated model indicated that longer ballots distributed during the election had the largest effect on the odds of 'HMI' errors. The remaining error categories (i.e., 'Machine' and 'Marking') had their odds both increase and decrease by different measures of ballot length which may indicate that these errors may have had additional causes that must be considered in future analyses, such as equipment specific characteristics, level of voter experience with a voting method, and/or the extent and effectiveness of election education materials. 


\section{Conclusion}

The implications of these findings are that in the 2018 RI Midterm elections, voters in municipalities with high urbanicity or in municipalities that distributed lengthy ballots had larger odds of experiencing voting errors, specifically more human-machine interaction (HMI) errors. Providing longer ballots increases the voter's ability to participate in democracy, although the consequence is an increase in voting errors which can lead to long wait times and voter disenfranchisement (Everett, Byrne, \& Greene, 2006; Ansolabehere \& Shaw, 2016). This investigation into the 2018 RI Midterm election indicates that, in areas with long ballots and high urbanicity, measures of ballot length should be used to influence strategies in election preparation and resource allocation techniques (e.g., polling places receive advanced voter education materials, additional poll workers, and voting equipment). This research provides an initial understanding of how ballot length impacted voting errors during the 2018 RI Midterm elections, stating that there is evidence that ballot length increases the odds of experiencing voting errors, regardless of location specific demographic. Although more work is required to fully understand how voting errors occur and their impacts are on the voting system.

A limitation in this study is the method by which voting error is defined. Due to the data source being an anonymous account of ballot scanning events, it is impossible to determine a voter's intention. For this reason, all overvotes and blank ballots were considered voting errors regardless of voter intention. This limitation could be resolved by performing controlled experiments in which participants are interviewed during or after the scanning process to identify their intentions throughout the marking process. Additionally, specific voter characteristics such as their level of experience with the ballot type or ballot 
scanner cannot be captured from the anonymous data. These factors may impact the odds of experiencing voting errors, although must be observed via controlled experimentation to protect voter anonymity. Another limitation within this analysis is that the undervote voting error (i.e., when some questions on a ballot are not marked while others are) was uncaptured by the DS200 for the 2018 RI Midterms. The method of data collection also presents a limitation, as the election considered was a Midterm election. Therefore, the results cannot be assumed to imply anything about other elections (e.g., General, Primary, Special) as each election type has several points of variation (e.g., turnout, perceived question importance, public awareness of the election).

With these limitations in mind, there is a plethora of future work that can build from the analysis in this research article. By simply including additional variables regarding ballot design and ballot measure information (i.e., the topic and information provided in a question), additional models can be developed to assess how a ballot impacts the odds of voting errors from a more holistic perspective. Additional research can also be conducted for different types of elections as well as in controlled environments. By assessing and comparing different election types, the most impactful errors across elections in general can be identified. Controlled experiments allow for the collection of participant demographic information which can also be recorded on a per participant basis and matched with their scanning event rather than on an aggregate level such as in real elections. With the inclusion of more specific demographic variables, a participant's history of voting, in depth ballot design variables, and ballot length variables, a more comprehensive and descriptive model could be determined to generate and establish a predictive model. While this research assesses data generated from the 2018 RI Midterm 
elections, the implications apply to elections in other states that use voting systems like those used in RI. There are many other states that utilize paper ballots and scanners (e.g., North Carolina, Arizona, Nebraska) that have increased voter populations with different demographic nuances, multiple urban areas per state and increased proportion of rural areas, and even structural differences in decision making in terms of state verses municipalities' thus providing ample opportunities for comparative studies and verification.

As demonstrated in ballot design and voting equipment literature, many voting systems have flaws. Due to concerns of both election officials and voters regarding newer and alternative voting systems, equipment use has begun to shift back to paper-based systems. Overlooking the impact ballot length on voting systems can lead to an entirely new set of concerns causing millions of voters to experience errors and delays throughout the voting process, providing voters with a false sense of system failure. Election systems are complex and, as technology changes, continue to grow in that complexity. Like any system, there are many critical components in the elections system that must be investigated prior to the accomplishment of a stable method for casting a vote. Rather than a continuous development of new voting methods, investigations and improvements on the voting methods that are currently in place across the U.S. are critical for voter trust, election security, and resources. This work provides an analysis of a mostly unexplored area of ballot research in the U.S. in assessing the effect of ballot length on voting error. This work implores and seeks to spark more in-depth assessments of election systems currently in place and the components that they are comprised of and how that impacts voter error within an election system at all levels of government. 


\section{References}

“About Language Minority Voting Rights.” The United States Department of Justice, 26

Feb. 2018, www.justice.gov/crt/about-language-minority-voting-rights.

Acemyan, Claudia Ziegler, \& Philip Kortum. 2017. “Assessing the Usability of the Hart InterCivic ESlate During the 2016 Presidential election." Proceedings of the Human Factors and Ergonomics Society Annual Meeting 61: 1404-1408. doi:10.1177/1541931213601835.

Acemyan, Claudia Ziegler, Philip Kortum, Michael D Byrne, \& Dan S Wallach. 2015. "From Error to Error: Why Voters Could Not Cast a Ballot and Verify Their Vote With Helios, Prêt à Voter, and Scantegrity II.” Journal of Election Technology and Systems (JETS) 3(2).

Alvarez, Michael R, Dustin Beckett, \& Charles Stewart. 2013. "Voting Technology, Vote-by-Mail, and Residual Votes in California, 1990-2010." Political Research Quarterly 66(3): 658-70.

Ansolabehere, Stephen, \& Charles Stewart. 2005. "Residual Votes Attributable to Technology." The Journal of Politics 67: 365-389. doi:10.1111/j.14682508.2005.00321.x.

Ansolabehere, Stephen, \& Shaw, Daron. 2016. “Assessing (and fixing?) Election Day lines: Evidence from a survey of local election officials." Electoral Studies 41: 111. doi:10.1016/j.electstud.2015.10.010

Belton, M Grant, Philip Kortum, \& Claudia Acemyan. 2015. "How Hard Can It Be to Place a Ballot into a Ballot Box?: Usability of Ballot Boxes in Tamper Resistant Voting Systems.” Journal of Usability Studies 10(4): 129-39. 
Brady, Henry E. 2000. "Report on Voting and Ballot Form in Palm Beach County." Brockington, David. 2003. "A Low Information Theory of Ballot Position Effect." Political Behavior 25(1).

Bullock III, Charles S, \& MV Hood III. 2002. “One Person-No Vote; One Vote; Two Votes: Voting Methods, Ballot Types, and Undervote Frequency in the 2000 Presidential election.” Social Science Quarterly 83(4): 981-93.

Cassidy, C. A., Long, C., \& Balsamo, M. 2018. “Long lines, machine breakdowns mar vote on Election Day." Providence Journal (November 07, 2018). https://www.providencejournal.com/news/20181106/long-lines-machinebreakdowns-mar-vote-on-election-day

Conrad, Frederick G, Bederson, Benjamin B, Lewis, Brian, Peytcheva, Emilia, Traugott, Michael W, Hanmer, Michael J, Herrnson, Paul S, \& Richard G Niemi. 2008. "Electronic voting eliminates hanging chads but introduces new usability challenges." Human-Computer Studies 67: 111-124.

DeSilver, Drew. 2016. "Most U.S. Voters Use Electronic or Optical-Scan Ballots.” Pew Research Center (November 8, 2016). www.pewresearch.org/facttank/2016/11/08/on-election-day-most-voters-use-electronic-or-optical-scanballots/.

Edelstein, William A., \& Arthur D. Edelstein. 2008. “Touchscreen Voting Machines Cause Long Lines and Disenfranchise Voters.” (October). 
Election Systems and Software. (2011). DS200 Precinct Ballot Scanner Election Day

Training Manual.

https://sos.idaho.gov/elect/clerk/DS200\%20Procedures/U3400_TRN00_DS200_Election. pdf

Emspak, Jesse. 2016. “Why Not Paper Ballots? America's Weird History of Voting Machines.” LiveScience, Purch (November 8, 2016).

www.livescience.com/56789-weird-history-of-voting-machines.html.

Everett, Sarah P, Michael D Byrne, \& Kristen K Greene. 2006. "Measuring the Usability of Paper Ballots: Efficiency, Effectiveness, and Satisfaction.” Proceedings of the Human Factors and Ergonomics Society.

Everett, Sarah P, Greene, Kristen K, Byrne, Michael D, Wallach, Dan S, Derr, Kyle, Sandler, Daniel \& Ted Torous. 2008. "Electronic Voting Machines versus Traditional Methods: Improved Preference, Similar Performance.” Computer Human Interaction.

Fessenden, Ford. 2000. “COUNTING THE VOTE: THE MACHINE; New Focus on Punch-Card System." The New York Times (November 19, 2000). Www.nytimes.com/2000/11/19/us/counting-the-vote-the-machine-new-focus-onpunch-card-system.html.

Gautam, R., \& Singh, P. 2015. "Human Machine Interaction.” International Journal of Science, Technology \& Management,4(1), 188-193.

Goggin, Stephen N, Michael D Byrne, Juan E Gilbert, Gregory Rogers, \& Jerome McClendon. 2008. "Comparing the Auditability of Optical Scan, Voter Verified Paper Audit Trail (VVPAT) and Video (VVVAT) Ballot Systems." 
Greene, Kristen K., et al. 2013. "How To Build an Undervoting Machine: Lessons from an Alternative Ballot Design." Journal of Election Technology and Systems 1(August): 38-52.Hall, Joseph L. 2006. "Design and the Support of Transparency in VVPAT Systems in the US Voting Systems Market."

Hamilton, James T., \& Helen F. Ladd. 1996. "Biased Ballots? The Impact of Ballot Structure on North Carolina Elections in 1992." Public Choice 87: 259-280. doi:10.1007/bf00118648.

Herrnson, Paul S, Michael J Hanmer, \& Richard G Niemi. 2012. "The Impact of Ballot Type on Voter Errors.” American Journal of Political Science 56(3): 716-30.

Herrnson, Paul S, Richard G Niemi, Michael J Hanmer, Peter L Francia, Benjamin B Bederson, Frederick G Conrad, \& Michael W Traugott. 2008. "Voters' Evaluations of Electronic Voting Systems.” American Politics Research 36(4): $580-611$.

Jackson, B. 2000. "Punch-card ballots notorious for inaccuracies." Cable News Network (November 15, 2000). http://www.cnn.com/2000/ALLPOLITICS/stories/11/15/jackson.punchcards/ Jastrzembski, Tiffany. 2004. "Human Factors and Voting Technology." Proceedings of the Human Factors and Ergonomics Society Annual Meeting 48(18): 2173-77.

Jones, Douglas W. 2010. “On Optical Mark-Sense Scanning.” Towards Trustworthy Elections Lecture Notes in Computer Science: 175-190. doi:10.1007/978-3-64212980-3_10.

Kimball, David C., \& Martha Kropf. 2003. "Ballot Design and Unrecorded Votes in the 2002 Midterm election.” American Political Science Association. 
Kimball, David C., \& Martha Kropf. 2005. "Ballot Design and Unrecorded Votes on Paper-Based Ballots.” Public Opinion Quarterly 69: 508-529. doi:10.1093/poq/nfi054.

Kimball, David C., \& Martha Kropf. 2008. "Voting Technology, Ballot Measures, and Residual Votes." American Politics Research 36(July): 479-509. doi:10.1177/1532673x08320405.

Kortum, Philip \& Michael D Byrne. 2016. “The Importance of Psychological Science in a Voter's Ability to Cast a Vote." Current Directions in Psychological Science 25(6): 467-473.

Lee, Seunghyun, et al. 2012. "EZ Ballot with Multimodal Inputs and Outputs." Proceedings of the 14th International ACM SIGACCESS Conference on Computers and Accessibility - ASSETS '12. doi:10.1145/2384916.2384960.

Lee, Seunghyun, et al. 2016. "Universal Design Ballot Interfaces on Voting Performance and Satisfaction of Voters with and without Vision Loss." Proceedings of the 2016 CHI Conference on Human Factors in Computing Systems. doi:10.1145/2858036.2858567.

Levine, Samantha. 2008. "Hanging Chads: As the Florida Recount Implodes, the Supreme Court Decides Bush v. Gore.” U.S. News \& World Report (January 17, 2008). www.usnews.com/news/articles/2008/01/17/the-legacy-of-hanging-chads.

Meadows, D. H., \& Wright, D. 2015. “Thinking in systems: A primer." White River Junction, VT: Chelsea Green Publishing.

Milita, Kerri. 2017. "Beyond Roll-off: Individual-Level Abstention on Ballot Measure Voting." Journal of Elections, Public Opinion and Parties 27(4): 448-465. 
Niemi, Richard G., \& Paul S. Herrnson. 2003. "Beyond the Butterfly: The Complexity of U.S. Ballots." Perspective on Politics 1: 317-326. doi:10.1017/s1537592703000239.

"Our Voting System." Clay County Supervisor of Elections, www.clayelections.com/Voters/Our-Voting-System.

Payson-Denney, Wade. 2015. "Who Really Won Bush-Gore Election? - CNNPolitics." CNN (October 31, 2015). www.cnn.com/2015/10/31/politics/bush-gore-2000election-results-studies/index.html.

Peng, Chao-Ying Joanne, et al. 2002. "An Introduction to Logistic Regression Analysis and Reporting." The Journal of Educational Research 96: 3-14. doi:10.1080/00220670209598786.

Redish, Janice (Ginny), Dana E Chisnell, Sharon J Laskowski, and Svetlana Lowry. 2010. "Plain Language Makes a Difference When People Vote." Journal of Usability Studies 5(3): 81-103.

Reilly, Shauna and Sean Richey. 2011. "Ballot Question Readability and Roll-off: The Impact of Language Complexity." Political Research Quarterly 64(1): 59-67.

"Rhode Island Buys 590 New Voting Machines." 2016. AP News, Associated Press (July 21, 2016). apnews.com/25d780c61bbb44f78d7ed55c76a3b189.

"Rhode Island Election Officials Urge Voters to Send in Mail Ballots Soon.” 2016. WPRO (November 2, 2016). www.630wpro.com/2016/11/02/rhode-islandelection-officials-urge-voters-to-send-in-mail-ballots-soon/.

"Rhode Island sees 'decent' voter turnout in midterm." 2018. AP News (November 28, 2018). https://www.apnews.com/1de2ee797d284189b77e27c9e0ec8199 
Roberts, Jason M. 2009. "Bicameralism, Ballot Type, and Split-Ticket Voting."

Selb, Peter. 2008. "Supersized Votes: Ballot Length, Uncertainty, and Choice in Direct Legislation Elections." Public Choice 135: 319-336. doi:10.1007/s11127-007$9265-7$.

Shocket, Peter A, Neil R Heighberger, and Clyde Brown. 1992. "The Effect of Voting Technology On Voting Behavior in a Simulated Multi-Candidate City Council Election: A Political Experiment of Ballot Transparency." Political Research Quarterly 45(2): 521-37.

Sinclair, Robert C., et al. 2000. “An Electoral Butterfly Effect.” Nature 408: 665-666. doi: $10.1038 / 35047160$.

Summers, Kathryn, Dana Chisnell, Drew Davies, Noel Alton, and Megan Mckeever. 2014. "Making Voting Accessible: Designing Digital Ballot Marking for People with Low Literacy and Mild Cognitive Disabilities." Journal of Election Technology and Systems 2(2): 11-33.

U.S. Election Assistance Commission. 2018. "2018 Election Administration and Voting Survey”. https://www.eac.gov/research-and-data/datasets-codebooks-and-surveys/

“U.S. States by Density 2019.” 2019. http://worldpopulationreview.com/states/statedensities/

"Voting and Registration in the Election of November 2016." 2018. Census Bureau QuickFacts, United States Census Bureau (October 11, 2018). www.census.gov/data/tables/time-series/demo/voting-and-registration/p20580.html. 
"Voting Equipment." 2018. National Conference of State Legislatures (August 20, 2018). www.ncsl.org/research/elections-and-campaigns/voting-equipment.aspx.

"Voting methods and equipment by state." (n.d.). https://ballotpedia.org/Voting_methods_and_equipment_by_state

“Voting Technology.” 2019. MIT Election Lab (January 8, 2019). electionlab.mit.edu/research/voting-technology.

Wand, Jonathan N., et al. 2001. "The Butterfly Did It: The Aberrant Vote for Buchanan in Palm Beach County, Florida.” The American Political Science Review 95(December): 793-810.

Wang, Kai, et al. 2010. "OpenScan: A Fully Transparent Optical Scan Voting System." Electronic Voting Technology/Workshop on Trustworthy Elections.

Wang, Y. 2005. A multinomial logistic regression modeling approach for anomaly intrusion detection. Computers \& Security,24(8), 662-674. doi:10.1016/j.cose.2005.05.003 
Appendix A

Processed DS200 Log File Data Using BOOTH Voting Package

\begin{tabular}{|c|c|c|}
\hline $\begin{array}{c}\text { Duration } \\
\text { (mm:ss) }\end{array}$ & Scan Type & Ballot Cast Status \\
\hline 00:04 & No Error & Successful \\
\hline $02: 30$ & Ballot Jam. Please check the paper path. & Jam \\
\hline 00:03 & No Error & Successful \\
\hline 00:03 & No Error & Successful \\
\hline 00:03 & No Error & Successful \\
\hline 00:03 & No Error & Successful \\
\hline 00:02 & No Error & Successful \\
\hline 00:05 & Voter Accepted Blank Ballot & Successful \\
\hline 00:03 & No Error & Successful \\
\hline 00:03 & No Error & Successful \\
\hline 00:03 & No Error & Successful \\
\hline 00:03 & No Error & Successful \\
\hline 00:07 & Voter Accepted Overvoted Ballot & Successful \\
\hline 00:04 & No Error & Successful \\
\hline 00:02 & No Error & Successful \\
\hline 00:02 & No Error & Successful \\
\hline 00:02 & No Error & Successful \\
\hline 00:02 & No Error & Successful \\
\hline 00:03 & No Error & Successful \\
\hline 00:03 & No Error & Successful \\
\hline 00:02 & No Error & Successful \\
\hline 00:03 & No Error & Successful \\
\hline 00:03 & No Error & Successful \\
\hline 00:03 & No Error & Successful \\
\hline 00:03 & No Error & Successful \\
\hline 00:03 & No Error & Successful \\
\hline 00:02 & No Error & Successful \\
\hline
\end{tabular}


Appendix B

Sample Ballot from the 2018 Rhode Island Midterm elections

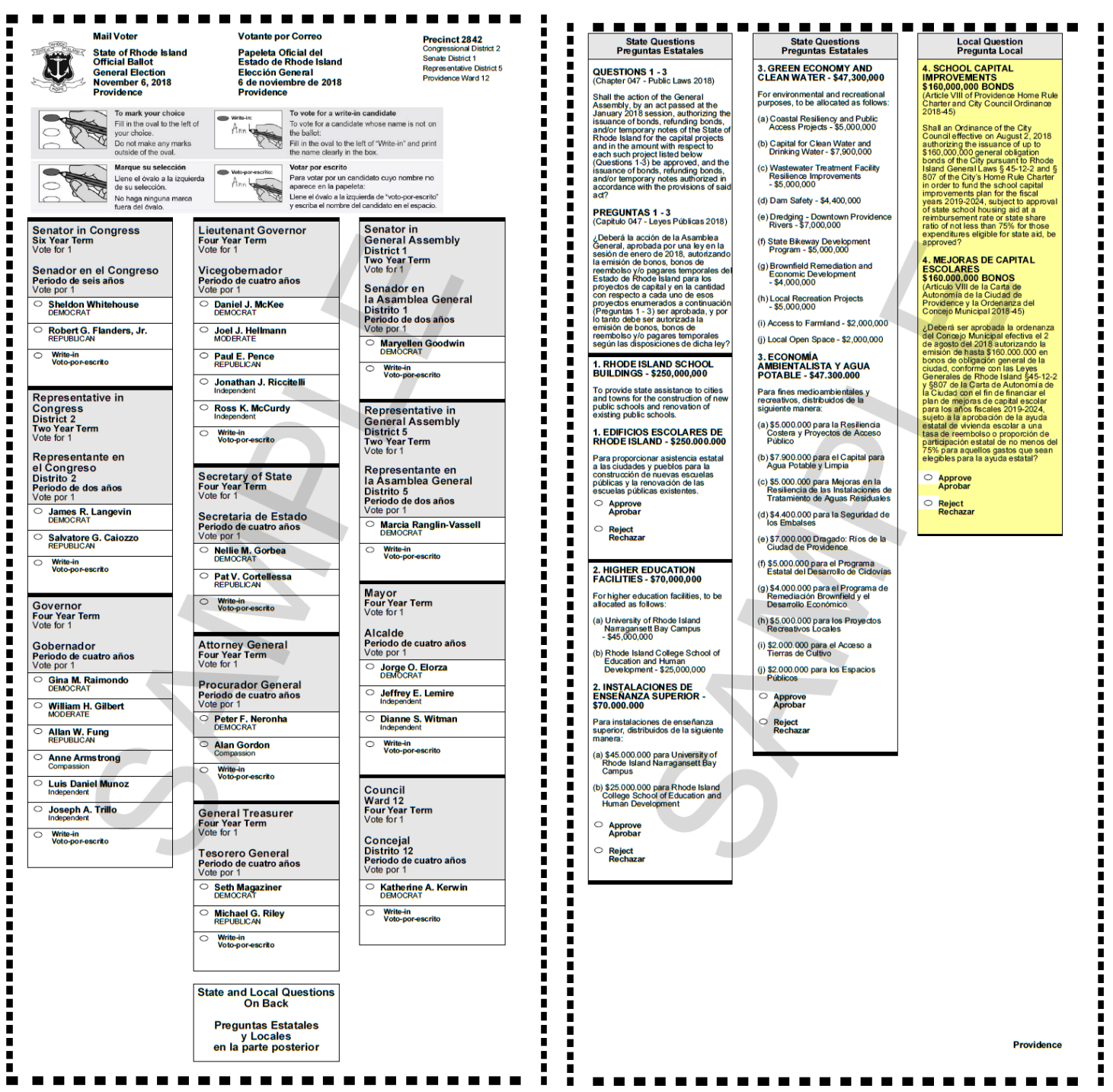


Appendix C

Ballot Length Metrics Data

\begin{tabular}{|c|c|c|c|c|c|c|c|c|c|c|}
\hline $\begin{array}{l}\text { Precin } \\
\text { ct } \\
\text { (Coded } \\
\text { ) }\end{array}$ & $\begin{array}{l}\text { Page } \\
\text { s }\end{array}$ & $\begin{array}{l}\text { Sheet } \\
\text { s }\end{array}$ & $\begin{array}{l}\text { Candida } \\
\text { te } \\
\text { Question } \\
\text { S } \\
\end{array}$ & $\begin{array}{l}\text { State } \\
\text { Questio } \\
\text { ns }\end{array}$ & $\begin{array}{l}\text { Local } \\
\text { Questio } \\
\text { ns }\end{array}$ & $\begin{array}{l}\text { Bilingu } \\
\text { al }\end{array}$ & $\begin{array}{l}\text { Total } \\
\text { Questio } \\
\text { n }\end{array}$ & $\begin{array}{l}\text { Candida } \\
\text { te Select }\end{array}$ & $\begin{array}{l}\text { Total } \\
\text { Selec } \\
t\end{array}$ & $\begin{array}{l}\text { Total } \\
\text { Word } \\
\text { s }\end{array}$ \\
\hline 1 & 2 & 1 & 12 & 3 & 3 & 0 & 18 & 15 & 21 & 729 \\
\hline 2 & 2 & 1 & 12 & 3 & 3 & 0 & 18 & 15 & 21 & 729 \\
\hline 3 & 2 & 1 & 12 & 3 & 3 & 0 & 18 & 15 & 21 & 729 \\
\hline 4 & 2 & 1 & 12 & 3 & 3 & 0 & 18 & 15 & 21 & 729 \\
\hline 5 & 2 & 1 & 12 & 3 & 3 & 0 & 18 & 15 & 21 & 729 \\
\hline 6 & 2 & 1 & 13 & 3 & 0 & 0 & 16 & 19 & 22 & 627 \\
\hline 7 & 2 & 1 & 13 & 3 & 0 & 0 & 16 & 19 & 22 & 627 \\
\hline 8 & 2 & 1 & 13 & 3 & 0 & 0 & 16 & 19 & 22 & 627 \\
\hline 9 & 2 & 1 & 13 & 3 & 0 & 0 & 16 & 19 & 22 & 627 \\
\hline 10 & 2 & 1 & 13 & 3 & 0 & 0 & 16 & 19 & 22 & 627 \\
\hline 11 & 2 & 1 & 13 & 3 & 0 & 0 & 16 & 19 & 22 & 627 \\
\hline 12 & 2 & 1 & 13 & 3 & 0 & 0 & 16 & 19 & 22 & 627 \\
\hline 13 & 2 & 1 & 13 & 3 & 0 & 0 & 16 & 19 & 22 & 627 \\
\hline 14 & 2 & 1 & 13 & 3 & 0 & 0 & 16 & 19 & 22 & 627 \\
\hline 15 & 2 & 1 & 11 & 3 & 0 & 0 & 14 & 18 & 21 & 614 \\
\hline 16 & 2 & 1 & 11 & 3 & 0 & 0 & 14 & 18 & 21 & 614 \\
\hline 17 & 2 & 1 & 11 & 3 & 0 & 0 & 14 & 18 & 21 & 614 \\
\hline 18 & 2 & 1 & 11 & 3 & 0 & 0 & 14 & 18 & 21 & 614 \\
\hline 19 & 2 & 1 & 11 & 3 & 0 & 0 & 14 & 18 & 21 & 614 \\
\hline 20 & 2 & 1 & 11 & 3 & 1 & 1 & 15 & 11 & 15 & 110 \\
\hline 21 & 2 & 1 & 11 & 3 & 1 & 1 & 15 & 11 & 15 & 110 \\
\hline 22 & 2 & 1 & 11 & 3 & 1 & 1 & 15 & 11 & 15 & 110 \\
\hline 23 & 2 & 1 & 11 & 3 & 1 & 1 & 15 & 11 & 15 & 110 \\
\hline 24 & 2 & 1 & 11 & 3 & 1 & 1 & 15 & 11 & 15 & 110 \\
\hline 25 & 2 & 1 & 11 & 3 & 1 & 1 & 15 & 11 & 15 & 110 \\
\hline 26 & 2 & 1 & 11 & 3 & 1 & 1 & 15 & 11 & 15 & 110 \\
\hline 27 & 2 & 1 & 11 & 3 & 1 & 1 & 15 & 11 & 15 & 110 \\
\hline 28 & 2 & 1 & 11 & 3 & 1 & 1 & 15 & 11 & 15 & 110 \\
\hline 29 & 2 & 1 & 11 & 3 & 1 & 1 & 15 & 11 & 15 & 110 \\
\hline 30 & 2 & 1 & 11 & 3 & 1 & 1 & 15 & 11 & 15 & 110 \\
\hline 31 & 2 & 1 & 11 & 3 & 1 & 1 & 15 & 11 & 15 & 110 \\
\hline 32 & 2 & 1 & 11 & 3 & 1 & 1 & 15 & 11 & 15 & 110 \\
\hline
\end{tabular}




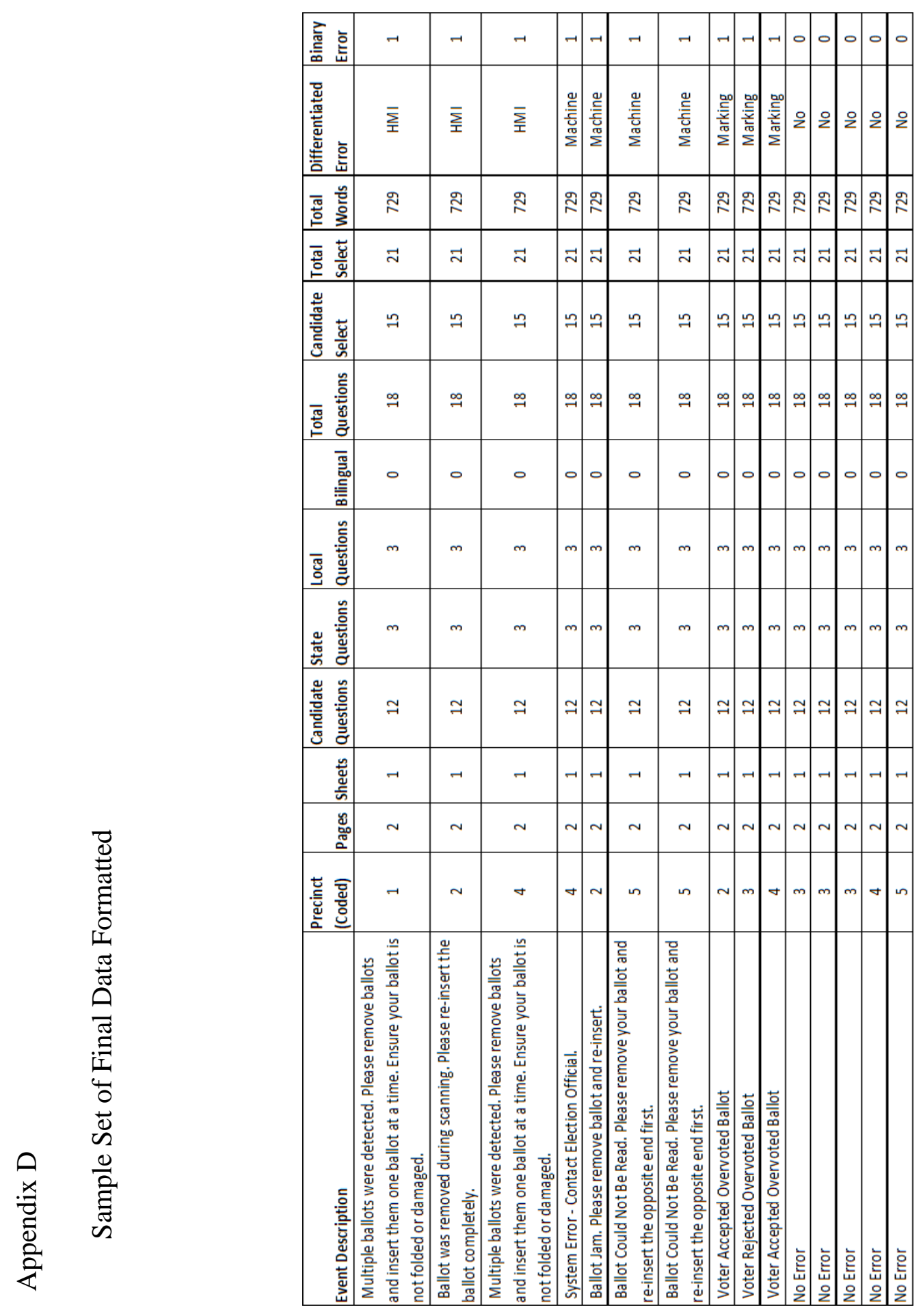




\section{Appendix E}

Ballot Scanner Codes, Categorization, and Observation Counts

\begin{tabular}{|c|c|c|c|}
\hline & \multirow{3}{*}{$\begin{array}{l}\text { Scanner Event Codes } \\
\text { No Error }\end{array}$} & \\
\hline & & & \multirow{2}{*}{ Count } \\
\hline \multirow{17}{*}{$\begin{array}{l}\text { Event } \\
\text { Type }\end{array}$} & No Error & & \\
\hline & \multirow{8}{*}{$\begin{array}{l}\text { Machine } \\
\text { Error }\end{array}$} & Ballot Jam. Please check the paper path. & 269 \\
\hline & & System Error - Contact Election Official. & 8 \\
\hline & & Ballot Jam. Please remove ballot and re-insert. & 71 \\
\hline & & $\begin{array}{l}\text { Ballot Could Not Be Read. Please remove your ballot and re- } \\
\text { insert the opposite end first. }\end{array}$ & 4229 \\
\hline & & $\begin{array}{l}\text { Error scanning ballot. Please remove your ballot and re-insert } \\
\text { the opposite end first. Ensure all stubs are removed from the } \\
\text { ballot. }\end{array}$ & 1677 \\
\hline & & Shutdown initiated & 5 \\
\hline & & Ballot too short Please remove ballot. & 19 \\
\hline & & Voting Machine Not Programmed For Your Ballot & 236 \\
\hline & \multirow{5}{*}{$\begin{array}{l}\text { Marking } \\
\text { Error }\end{array}$} & Voter Rejected Overvoted Ballot & 2159 \\
\hline & & Voter Accepted Overvoted Ballot & 3147 \\
\hline & & Voter Rejected Blank Ballot & 637 \\
\hline & & Voter Accepted Blank Ballot & 1906 \\
\hline & & Automatically rejected Ballot with Unreadable mark & 10014 \\
\hline & \multirow{3}{*}{$\begin{array}{l}\text { HMI } \\
\text { Error }\end{array}$} & $\begin{array}{l}\text { Ballot was not inserted far enough. Please remove your ballot } \\
\text { and re-insert it completely. }\end{array}$ & 675 \\
\hline & & $\begin{array}{l}\text { Ballot was removed during scanning. Please re-insert the } \\
\text { ballot completely. }\end{array}$ & 1678 \\
\hline & & $\begin{array}{l}\text { Multiple ballots were detected. Please remove ballots and } \\
\text { insert them one ballot at a time. Ensure your ballot is not } \\
\text { folded or damaged. }\end{array}$ & 2694 \\
\hline
\end{tabular}

